\title{
Nitrogen isotope fractionation in protoplanetary disks
}

\author{
Ruud Visser ${ }^{1}$, Simon Bruderer ${ }^{2}$, Paolo Cazzoletti ${ }^{2}$, Stefano Facchini ${ }^{2}$, Alan N. Heays ${ }^{3}$, and Ewine F. van Dishoeck ${ }^{4,2}$ \\ ${ }^{1}$ European Southern Observatory, Karl-Schwarzschild-Straße 2, 85748 Garching, Germany \\ e-mail: ruudvisser@gmail.com \\ 2 Max-Planck-Institut für extraterrestrische Physik, Giessenbachstraße 1, 85748 Garching, Germany \\ ${ }^{3}$ Observatoire de Paris, LERMA, UMR 8112 du CNRS, 92195 Meudon, France \\ ${ }^{4}$ Leiden Observatory, Leiden University, PO Box 9513, 2300 RA Leiden, The Netherlands
}

Received 5 September 2017 / Accepted 8 February 2018

\begin{abstract}
Aims. The two stable isotopes of nitrogen, ${ }^{14} \mathrm{~N}$ and ${ }^{15} \mathrm{~N}$, exhibit a range of abundance ratios both inside and outside the solar system. The elemental ratio in the solar neighborhood is 440. Recent ALMA observations showed $\mathrm{HCN} / \mathrm{HC}{ }^{15} \mathrm{~N}$ ratios from 83 to 156 in six $\mathrm{T}$ Tauri and Herbig disks and a $\mathrm{CN} / \mathrm{C}^{15} \mathrm{~N}$ ratio of $323 \pm 30$ in one T Tauri star. We aim to determine the dominant mechanism responsible for these enhancements of ${ }^{15} \mathrm{~N}$ : low-temperature exchange reactions or isotope-selective photodissociation of $\mathrm{N}_{2}$.

Methods. Using the thermochemical code DALI, we model the nitrogen isotope chemistry in circumstellar disks with a 2D axisymmetric geometry. Our chemical network is the first to include both fractionation mechanisms for nitrogen. The model produces abundance profiles and isotope ratios for several key N-bearing species. We study how these isotope ratios depend on various disk parameters. Results. The formation of $\mathrm{CN}$ and $\mathrm{HCN}$ is closely coupled to the vibrational excitation of $\mathrm{H}_{2}$ in the UV-irradiated surface layers of the disk. Isotope fractionation is completely dominated by isotope-selective photodissociation of $\mathrm{N}_{2}$. The column density ratio of $\mathrm{HCN}$ over $\mathrm{HC}^{15} \mathrm{~N}$ in the disk's inner 100 au does not depend strongly on the disk mass, the flaring angle or the stellar spectrum, but it is sensitive to the grain size distribution. For larger grains, self-shielding of $\mathrm{N}_{2}$ becomes more important relative to dust extinction, leading to stronger isotope fractionation. Between disk radii of $\sim 50$ and $200 \mathrm{au}$, the models predict $\mathrm{HCN} / \mathrm{HC} \mathrm{C}^{15} \mathrm{~N}$ and $\mathrm{CN} / \mathrm{C}^{15} \mathrm{~N}$ abundance ratios consistent with observations of disks and comets. The $\mathrm{HCN} / \mathrm{HC}^{15} \mathrm{~N}$ and $\mathrm{CN} / \mathrm{C}^{15} \mathrm{~N}$ column density ratios in the models are a factor of 2-3 higher than those inferred from the ALMA observations.
\end{abstract}

Key words. protoplanetary disks - methods: numerical - astrochemistry - radiative transfer

\section{Introduction}

Nitrogen has two stable isotopes, ${ }^{14} \mathrm{~N}$ and ${ }^{15} \mathrm{~N}$, whose abundance ratio spans a wide range of values in the solar system: 50-280 in meteorites, 120-300 in interplanetary dust particles, $\sim 150$ in comets, 272 on Earth and 440 in the solar wind (Busemann et al. 2006; Floss et al. 2006; Manfroid et al. 2009; Marty et al. 2011; Mumma \& Charnley 2011; Füri \& Marty 2015). The solar wind value is representative of the gas out of which the solar system formed, so there must have been one or more mechanisms that acted to enhance ${ }^{15} \mathrm{~N}$ relative to ${ }^{14} \mathrm{~N}$ on Earth and in the other solid bodies.

Nitrogen isotope fractionation is also observed outside the solar system, from diffuse clouds to prestellar cores and circumstellar disks (Lucas \& Liszt 1998; Wampfler et al. 2014; Zeng et al. 2017; Guzmán et al. 2017; Hily-Blant et al. 2017). The lowest and highest ${ }^{14} \mathrm{~N} /{ }^{15} \mathrm{~N}$ ratio are a factor of 40 apart, clearly indicating various degrees of fractionation towards different sources. These observations were made in HCN, HNC, $\mathrm{CN}, \mathrm{NH}_{3}$ and $\mathrm{N}_{2} \mathrm{H}^{+}$, which are all trace species of nitrogen. The bulk reservoir likely consists of atomic $\mathrm{N}$ and $\mathrm{N}_{2}$, of which the isotopic composition remains unknown.

Two fractionation mechanisms have been proposed to explain the ${ }^{14} \mathrm{~N} /{ }^{15} \mathrm{~N}$ ratios inside and outside the solar system: lowtemperature isotope exchange reactions (Terzieva \& Herbst 2000; Roueff et al. 2015; Wirström \& Charnley 2018) and isotope-selective photodissociation of $\mathrm{N}_{2}$ (Liang et al. 2007; Heays et al. 2014). The low-temperature pathway is based on the difference in zero-point vibrational energies, such that heavier isotopologs are energetically favored over lighter isotopologs. This mechanism is well known for hydrogen and deuterium, leading e.g., to $\mathrm{HDO} / \mathrm{H}_{2} \mathrm{O}$ and $\mathrm{DCO}^{+} / \mathrm{HCO}^{+}$abundance ratios of up to a few orders of magnitude higher than the elemental $\mathrm{D} / \mathrm{H}$ ratio (Ceccarelli et al. 2014). The isotope-selective dissociation pathway, also called self-shielding, arises from a small shift in frequencies for the absorption lines through which ${ }^{14} \mathrm{~N}_{2}$ and ${ }^{14} \mathrm{~N}^{15} \mathrm{~N}$ are photodissociated. This shift allows photodissociation of ${ }^{14} \mathrm{~N}^{15} \mathrm{~N}$ to continue when the lines of ${ }^{14} \mathrm{~N}_{2}$ are saturated, causing an enhancement of atomic ${ }^{15} \mathrm{~N}$ over ${ }^{14} \mathrm{~N}$. The same mechanism, acting in $\mathrm{CO}$, has been suggested as an explanation for the oxygen isotope ratios in meteorites (Lyons \& Young 2005).

Chemical models of nitrogen isotope fractionation have been published for dense clouds and prestellar cores (Terzieva \& Herbst 2000; Rodgers \& Charnley 2004, 2008a,b; Wirström et al. 2012; Roueff et al. 2015; Wirström \& Charnley 2018), in all cases featuring low-temperature exchange reactions as the only fractionation mechanism. These models are generally successful at reproducing the fractionation observed in $\mathrm{NH}_{3}$ and $\mathrm{HCN}$, but have trouble reproducing some of the data on $\mathrm{N}_{2} \mathrm{H}^{+}$. Using estimated $\mathrm{N}_{2}$ self-shielding functions and an incomplete chemical network, Lyons et al. (2009) obtained an $\mathrm{HC}^{14} \mathrm{~N} / \mathrm{HC}^{15} \mathrm{~N}$ ratio of $\sim 350$ in a simplified circumstellar disk model. With new shielding functions and a larger network, Heays et al. (2014) saw $\mathrm{HC}^{14} \mathrm{~N} / \mathrm{HC}^{15} \mathrm{~N}$ ratios down to 50 in models of a single vertical cut through a disk. The observed range of $\mathrm{HC}^{14} \mathrm{~N} / \mathrm{HC}^{15} \mathrm{~N}$ column density ratios is $83 \pm 32$ to $156 \pm 71$ in a sample of six T Tauri 
and Herbig disks (Guzmán et al. 2017). For $\mathrm{C}^{14} \mathrm{~N} / \mathrm{C}^{15} \mathrm{~N}$, there is a single measurement of $323 \pm 20$ in a T Tauri disk (Hily-Blant et al. 2017).

We present here the first nitrogen isotope fractionation models for circumstellar disks with a 2D axisymmetric geometry, including both low-temperature exchange reactions and selfshielding of $\mathrm{N}_{2}$. We employ the thermochemical code DALI (Dust and Lines; Bruderer et al. 2012; Bruderer 2013) in a setup similar to that used by Miotello et al. (2014) to study the isotopologs of CO. Section 2 contains a full description of the physical framework and the chemical network. Abundance profiles and isotope ratios for a fiducial disk model are presented in Sect. 3. We pay particular attention to the three cyanides $\mathrm{HCN}, \mathrm{HNC}$ and $\mathrm{CN}$ because of the aforementioned recent observations of ${ }^{14} \mathrm{~N} /{ }^{15} \mathrm{~N}$ ratios in $\mathrm{HCN}$ and $\mathrm{CN}$ (Guzmán et al. 2017; Hily-Blant et al. 2017). Section 4 discusses the dominant fractionation mechanism, the match with observations, and the effects of changing various disk parameters. We summarize the main conclusions in Sect. 5.

\section{Model}

We simulate the nitrogen isotope chemistry in a set of protoplanetary disk models with the thermochemical code DALI (Dust and Lines; Bruderer et al. 2012; Bruderer 2013). Given a two-dimensional, axisymmetric density profile, DALI uses a Monte Carlo technique to compute the radiation field and dust temperature throughout the disk. The gas temperature is solved by iterating over the heating/cooling balance and the chemical abundances. DALI approximates the excitation of the main coolants through an escape probability approach, taking into account both collisions and radiative effects. Once the gas temperature and abundance calculations are completed, a raytracer synthesizes continuum and line observations at arbitrary distances and inclinations. The accuracy of DALI has been verified against benchmark problems and observations (Bruderer et al. 2012, 2014; Bruderer 2013; Fedele et al. 2013).

Our methods are generally the same as those developed by Miotello et al. (2014) for CO and its isotopologs, except the focus has shifted to N-bearing species. The following subsections summarize the physical framework and describe the revised chemical network.

\subsection{Physical framework}

The purpose of this work is to present a general exploration of the nitrogen isotope chemistry in protoplanetary disks, without focusing on any one particular source. Isotope effects depend primarily on the gas temperature and the UV flux, so we adopt a small grid of parameterized models to cover a range of values for both quantities (Tables 1 and 2).

The disk models have a power-law surface density $\left(\Sigma \propto R^{-\gamma}\right)$ with an exponential taper beyond $R_{\mathrm{c}}=60$ au (Andrews et al. 2011). The gas densities follow a vertical Gaussian profile with a scale height angle $h=h_{\mathrm{c}}\left(R / R_{\mathrm{c}}\right)^{\psi}$, where $\psi$ varies from 0.1 to 0.3 to cover a range of flaring angles. The dust consists of populations of small grains $(0.005-1 \mu \mathrm{m})$ and large grains $(1-1000 \mu \mathrm{m}$; D'Alessio et al. 2006). The small grains have the same scale height $h$ as the gas, while the large grains have settled to a reduced scale height of $\chi h$ with $\chi=0.2$. We explore different grain size distributions by varying the mass fraction of large grains $\left(f_{\mathrm{L}}\right)$ from $10 \%$ to $99 \%$. The global gas-to-dust mass ratio is constant at 100 . Within the grid of models, the total disk mass varies between $10^{-4}, 10^{-3}$ and $10^{-2} M_{\odot}$. All other parameters
Table 1. Summary of model parameters.

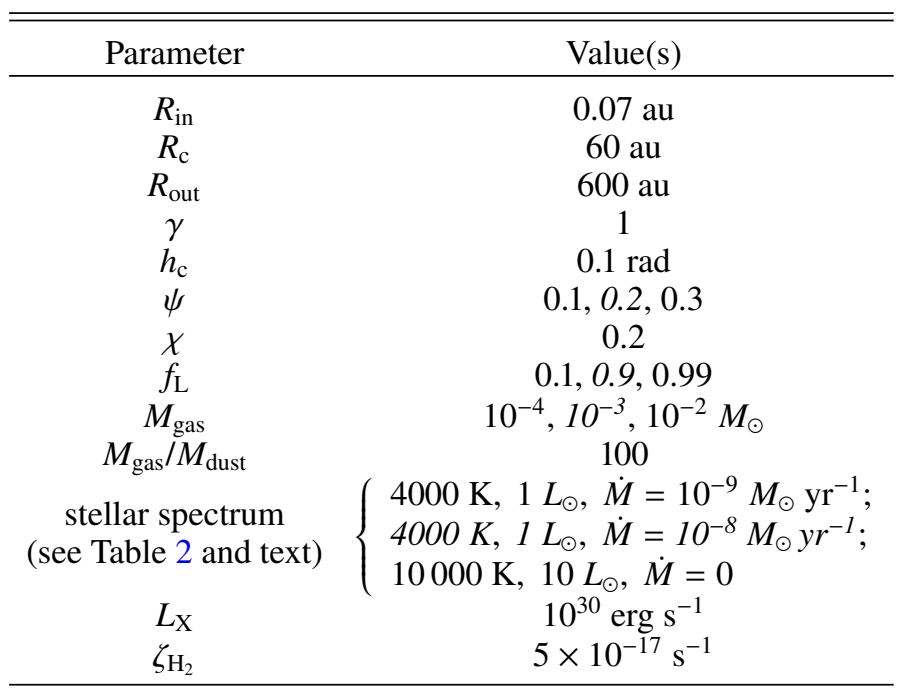

Notes. Values in italics are used in the fiducial model.

Table 2. Luminosities integrated over various wavelength ranges for the model spectra.

\begin{tabular}{cccccc}
\hline \hline Type & $\begin{array}{c}\dot{M} \\
\left(M_{\odot} \mathrm{yr}^{-1}\right)\end{array}$ & $\begin{array}{c}L_{*} \\
\left(L_{\odot}\right)\end{array}$ & $\begin{array}{c}L_{\mathrm{acc}} \\
\left(L_{\odot}\right)\end{array}$ & $\begin{array}{c}L_{6-13.6 \mathrm{eV}} \\
\left(L_{\odot}\right)\end{array}$ & $\begin{array}{c}L_{912-1000 \AA} \\
\left(L_{\odot}\right)\end{array}$ \\
\hline Herbig & 0 & 10 & 0 & $7.7(-1)$ & $2.2(-3)$ \\
T Tauri & $1(-8)$ & 1.0 & $2.3(-1)$ & $1.8(-2)$ & $5.0(-5)$ \\
T Tauri & $1(-9)$ & 1.0 & $2.3(-2)$ & $1.8(-3)$ & $5.0(-6)$ \\
T Tauri & $1(-10)$ & 1.0 & $2.3(-3)$ & $2.0(-4)$ & $5.0(-7)$ \\
T Tauri & 0 & 1.0 & 0 & $2.7(-5)$ & $1.8(-12)$ \\
\hline
\end{tabular}

Notes. The notation $a(-b)$ means $a \times 10^{-b}$.

are set to the same values as in Miotello et al. (2014), including a cosmic ray ionization rate of $5 \times 10^{-17} \mathrm{~s}^{-1}$ per $\mathrm{H}_{2}$, a stellar X-ray luminosity of $10^{30} \mathrm{erg} \mathrm{s}^{-1}$, and an interstellar UV flux typical for the solar neighborhood (Habing 1968).

The stellar spectra considered in our models consist of a blackbody spectrum of a given temperature and luminosity: $4000 \mathrm{~K}$ and $1 L_{\odot}$ for a T Tauri star and $10000 \mathrm{~K}$ and $10 L_{\odot}$ for a Herbig Ae/Be star (the same as in Miotello et al. 2014). The T Tauri spectra include an optional UV excess due to accretion. For a given accretion rate $\dot{M}$, we convert all gravitational potential energy into $10000 \mathrm{~K}$ blackbody radiation emitted uniformly over the stellar surface. The accretion luminosity is

$L_{\mathrm{acc}}=\frac{G M_{*} \dot{M}}{R_{*}}$.

The median accretion rate for $\mathrm{T}$ Tauri stars of $1 \mathrm{Myr}$ old is $10^{-8} M_{\odot} \mathrm{yr}^{-1}$ (Hartmann et al. 1998). Setting $M_{*}=1 M_{\odot}$ and $R_{*}=1.5 R_{\odot}$, the accretion luminosity is $0.23 L_{\odot}$ integrated across all possible wavelengths or $0.018 L_{\odot}$ in the far-UV range from 6 to $13.6 \mathrm{eV}$.

Figure 1 shows the stellar spectra for a T Tauri star without UV excess, three $\mathrm{T}$ Tauri stars with different accretion rates, and a Herbig star. These spectra vary by orders of magnitude in flux between 912 and $1000 \AA$, the wavelength range critical for the photodissociation and self-shielding of $\mathrm{N}_{2}$ (Li et al. 2013; Heays et al. 2014). Table 2 lists the luminosities integrated over various wavelength ranges. 


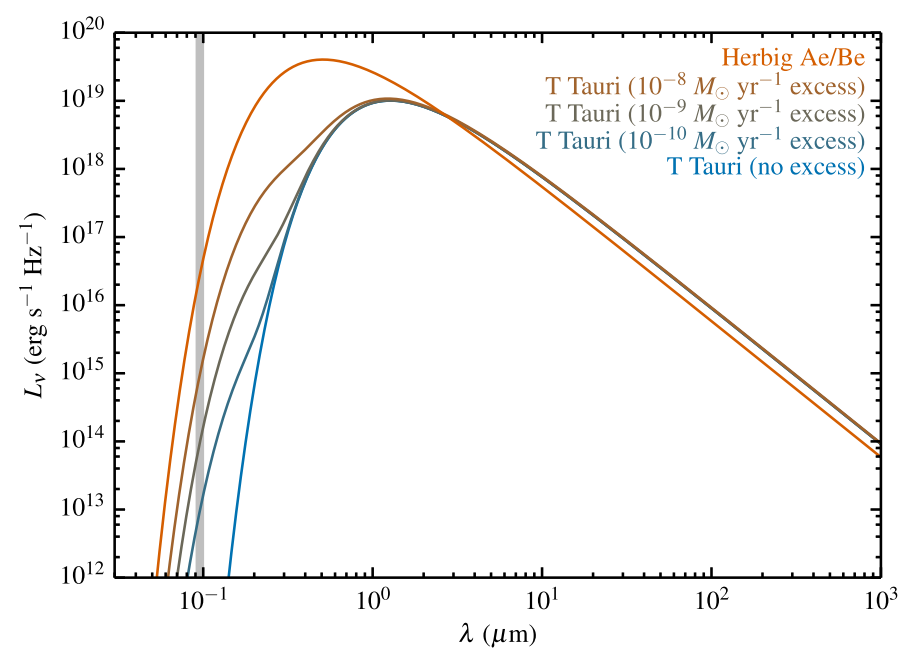

Fig. 1. Stellar spectra used in our model. The gray band marks the wavelength range of 912 to $1000 \AA$ for the photodissociation of $\mathrm{N}_{2}$.

\subsection{Chemical network}

\subsubsection{Reduced network for $\mathrm{C} / \mathrm{N} / \mathrm{O}$ chemistry}

For their exploration of the $\mathrm{CO}$ isotopolog chemistry, Miotello et al. (2014) extended the reaction network of Bruderer et al. (2012) to include ${ }^{13} \mathrm{C},{ }^{17} \mathrm{O}$, and ${ }^{18} \mathrm{O}$. The Bruderer et al. (2012) network itself is a reduced version of the UMIST Database for Astrochemistry (UDfA; Woodall et al. 2007; McElroy et al. 2013), optimized to yield accurate abundances for CO and related species with a minimum of computational effort. However, it lacks several species and reactions crucial to the chemistry of $\mathrm{HCN}, \mathrm{HNC}$ and $\mathrm{CN}$ (see review by Loison et al. 2014).

Our model combines the reaction networks of Bruderer et al. (2012) and Loison et al. (2014) into a new reduced network for the $\mathrm{C} / \mathrm{N} / \mathrm{O}$ chemistry throughout a protoplanetary disk. Crosschecks against the full UMIST database at a dozen sets of physical conditions (representative of different physical regimes within the disk) confirmed that our network contains all reactions that affect the abundances of $\mathrm{HCN}, \mathrm{HNC}$ and $\mathrm{CN}$ by more than a few per cent. Any effects smaller than this margin are lost in the overall model uncertainties.

The network contains both gas-phase and grain-surface processes, as described in Appendix A.3.1 of Bruderer et al. (2012). The gas-phase part consists of standard neutral-neutral and ionmolecule chemistry; reactions with vibrationally excited $\mathrm{H}_{2}$; charge exchange and $\mathrm{H}$ transfer with polycyclic aromatic hydrocarbons; photodissociation and photoionization; and reactions induced by X-rays and cosmic rays. All neutral molecules can freeze out, and desorption back into the gas phase can occur thermally or non-thermally via UV photons and cosmic rays. Grain-surface chemistry is limited to $\mathrm{H}_{2}$ formation, hydrogenation of $\mathrm{CN}$ to $\mathrm{HCN}$, and step-wise hydrogenation of atomic $\mathrm{C}, \mathrm{N}$ and $\mathrm{O}$ to $\mathrm{CH}_{4}, \mathrm{NH}_{3}$ and $\mathrm{H}_{2} \mathrm{O}$ (Bruderer et al. 2012). We adopt desorption energies from the Kinetic Database for Astrochemistry (KIDA; Wakelam et al. 2012), including $1600 \mathrm{~K}$ for $\mathrm{CN}$, $2050 \mathrm{~K}$ for $\mathrm{HCN}$ and $\mathrm{HNC}$, and $5500 \mathrm{~K}$ for $\mathrm{NH}_{3}$.

The interaction of cosmic rays or X-rays with $\mathrm{H}_{2}$ generates a local UV field even in parts of the disk that are shielded from stellar and interstellar UV radiation. The UDfA rate equation for the CR- and X-ray-induced photodissociation of CO is a fit to a set of tabulated values from Gredel et al. (1987). These authors reported faster rates for higher temperatures, but the new calculations from Heays et al. (2014) show no dependence on
Table 3. Initial abundances relative to the total number of hydrogen atoms.

\begin{tabular}{cccc}
\hline \hline Species & Abundance & Species & Abundance \\
\hline $\mathrm{H}_{2}$ & $5.000(-01)$ & ${ }^{13} \mathrm{CN}$ & $9.565(-10)$ \\
$\mathrm{He}$ & $1.400(-01)$ & ${ }^{13} \mathrm{C}^{15} \mathrm{~N}$ & $2.126(-12)$ \\
$\mathrm{H}_{2} \mathrm{O}$ ice & $2.500(-04)$ & $\mathrm{HCN}$ & $1.000(-08)$ \\
$\mathrm{CO}$ & $1.000(-04)$ & $\mathrm{HC}^{15} \mathrm{~N}$ & $2.222(-11)$ \\
${ }^{13} \mathrm{CO}$ & $1.449(-06)$ & $\mathrm{H}^{13} \mathrm{CN}$ & $1.449(-10)$ \\
$\mathrm{NH}_{3}$ ice & $9.900(-06)$ & $\mathrm{H}^{13} \mathrm{C}^{15} \mathrm{~N}$ & $3.220(-13)$ \\
${ }^{15} \mathrm{NH}_{3}$ ice & $2.200(-08)$ & $\mathrm{H}_{3}^{+}$ & $1.000(-08)$ \\
$\mathrm{N}$ & $5.100(-06)$ & $\mathrm{HCO}^{+}$ & $9.000(-09)$ \\
${ }^{15} \mathrm{~N}$ & $1.133(-08)$ & $\mathrm{H}^{13} \mathrm{CO}^{+}$ & $1.304(-10)$ \\
$\mathrm{N}_{2}$ & $1.000(-06)$ & $\mathrm{C}_{2} \mathrm{H}$ & $8.000(-09)$ \\
$\mathrm{N}^{15} \mathrm{~N}$ & $4.444(-09)$ & ${ }^{13} \mathrm{CCH}^{15}$ & $1.159(-10)$ \\
$\mathrm{C}$ & $7.000(-07)$ & $\mathrm{C}^{13} \mathrm{CH}$ & $1.159(-10)$ \\
${ }^{13} \mathrm{C}$ & $1.014(-08)$ & $\mathrm{C}^{+}$ & $1.000(-09)$ \\
${ }^{\mathrm{PAH}}$ & $6.000(-07)$ & ${ }^{13} \mathrm{C}+$ & $1.449(-11)$ \\
$\mathrm{CH}_{4}$ & $1.000(-07)$ & $\mathrm{Mg}^{+}$ & $1.000(-11)$ \\
${ }^{13} \mathrm{CH} 4$ & $1.449(-09)$ & $\mathrm{Si}^{+}$ & $1.000(-11)$ \\
$\mathrm{CN} \mathrm{6}$ & $6.600(-08)$ & $\mathrm{S}^{+}$ & $1.000(-11)$ \\
$\mathrm{C}^{15} \mathrm{~N}$ & $1.467(-10)$ & $\mathrm{Fe}^{+}$ & $1.000(-11)$ \\
\hline
\end{tabular}

temperature. The Gredel et al. (1987) calculations appear not to have accounted for $\mathrm{H}_{2}$ shielding, or at least not for the effect of the gas temperature on the $\mathrm{H}_{2}$ shielding.

The temperature-independent rate coefficient $k$ for this process can be expressed as the product of the total ionization rate $\zeta$ (sum of cosmic ray and X-ray contributions) and the photodissociation efficiency $P$. To account for self-shielding, we fit a sigmoid function to the tabulated values of Heays et al. and some additional values for typical interstellar grain properties:

$P=\frac{56.14}{1+51100[x(\mathrm{CO})]^{0.792}}+4.3$

where $x(\mathrm{CO}) \equiv n(\mathrm{CO}) / n_{\text {gas }}$ is the $\mathrm{CO}$ abundance relative to the total number density of gas. The photodissociation efficiency varies smoothly from 5 at a $\mathrm{CO}$ abundance of a few $10^{-4}$ to 60 at abundances below $10^{-8}$. Grain growth can increase $P$ by up to a factor of 2 (Heays et al. 2014).

Our network includes vibrationally excited $\mathrm{H}_{2}$ in a two-level approximation, where $\mathrm{H}_{2}^{*}$ denotes a pseudo-level with an energy of $30163 \mathrm{~K}$ (London 1978). This energy can be used to overcome activation barriers as detailed in Appendix A.3.1 of Bruderer et al. (2012). An important example for the cyanide chemistry is the reaction between $\mathrm{N}$ and $\mathrm{H}_{2}$, whose barrier of $12650 \mathrm{~K}$ (Davidson \& Hanson 1990) would otherwise be insurmountable in the bulk of the disk. In our model, FUV pumping of $\mathrm{H}_{2}$ to $\mathrm{H}_{2}^{*}$ in the disk's surface layers enables the reaction with $\mathrm{N}$, and the product $\mathrm{NH}$ enters directly into the cyanide chemistry by reacting with $\mathrm{C}$ or $\mathrm{C}^{+}$to form $\mathrm{CN}$ or $\mathrm{CN}^{+}$(Appendix $\mathrm{C}$ ). Appendix $\mathrm{A}$ describes the treatment of $\mathrm{H}_{2}^{*}$ in more detail.

We run the chemistry for a typical disk lifetime of $1 \mathrm{Myr}$. The initial abundances are listed in Table 3 . These values are adopted from Cleeves et al. (2015), except $x(\mathrm{CO})$ is set to $1 \times 10^{-4}$ relative to total hydrogen.

\subsubsection{Addition of ${ }^{15} \mathrm{~N}$ and ${ }^{13} \mathrm{C}$}

Observationally, the ${ }^{14} \mathrm{~N} /{ }^{15} \mathrm{~N}$ ratio is often obtained from the optically thin emission of $\mathrm{H}^{13} \mathrm{CN}$ and $\mathrm{HC}^{15} \mathrm{~N}$. Analyzing the 
nitrogen isotope chemistry therefore requires the addition of both ${ }^{15} \mathrm{~N}$ and ${ }^{13} \mathrm{C}$ to the network. The oxygen isotopes are not necessary. We extended the reduced $\mathrm{C} / \mathrm{N} / \mathrm{O}$ network according to standard procedure (e.g., Le Bourlot et al. 1993; Röllig \& Ossenkopf 2013). This involves single substitutions of either ${ }^{14} \mathrm{~N}$ by ${ }^{15} \mathrm{~N}$ or ${ }^{12} \mathrm{C}$ by ${ }^{13} \mathrm{C}$, or substitution of both ${ }^{14} \mathrm{~N}$ and ${ }^{12} \mathrm{C}$, but not double substitutions of the same atom. For example, $\mathrm{N}_{2} \mathrm{H}^{+}$ expands into ${ }^{14} \mathrm{~N}_{2} \mathrm{H}^{+},{ }^{14} \mathrm{~N}^{15} \mathrm{NH}^{+}$and ${ }^{15} \mathrm{~N}^{14} \mathrm{NH}^{+}$. Our species of primary interest, $\mathrm{HCN}$, becomes $\mathrm{H}^{12} \mathrm{C}^{14} \mathrm{~N}, \mathrm{H}^{12} \mathrm{C}^{15} \mathrm{~N}, \mathrm{H}^{13} \mathrm{C}^{14} \mathrm{~N}$ and $\mathrm{H}^{13} \mathrm{C}^{15} \mathrm{~N}$. Table B.1 in Appendix B lists the full set of species in the network.

The reactions from the $\mathrm{C} / \mathrm{N} / \mathrm{O}$ network are expanded to include all possible isotope substitutions, under the condition that functional groups are preserved (Woods \& Willacy 2009). For example, the proton-transfer reaction $\mathrm{HC}^{15} \mathrm{~N}+\mathrm{N}_{2} \mathrm{H}^{+}$can only produce $\mathrm{HC}^{15} \mathrm{NH}^{+}+\mathrm{N}_{2}$, not $\mathrm{HCNH}^{+}+\mathrm{N}^{15} \mathrm{~N}$. If the reaction mechanism is unknown, then we follow the guidelines from Röllig \& Ossenkopf (2013): minimize the number of bonds broken and formed; favor transfer of $\mathrm{H}$ or $\mathrm{H}^{+}$over heavier atoms; and favor destruction of the weaker of two possible bonds. In the absence of experimental data, the rate constants for all isotopolog reactions are set to be the same as for the original reaction. In cases where multiple product channels are allowed, all channels are assigned an equal probability (Röllig \& Ossenkopf 2013).

\subsubsection{Isotope-exchange reactions}

At temperatures below $\sim 20 \mathrm{~K}$, isotope-exchange reactions tend to enhance the abundances of heavier isotopologs over their lighter counterparts. The most common astrophysical example is the exothermic reaction between ${ }^{13} \mathrm{C}^{+}$and $\mathrm{CO}$ to form $\mathrm{C}^{+}$and ${ }^{13} \mathrm{CO}$ (Watson et al. 1976). Its forward rate at low temperatures is faster than that of the return reaction, leading to carbon isotope fractionation in CO. Similar reactions can affect the ${ }^{14} \mathrm{~N} /{ }^{15} \mathrm{~N}$ ratio in $\mathrm{HCN}$ and other species.

Roueff et al. (2015) reviewed a set of 19 possible carbon and nitrogen isotope-exchange reactions, of which eleven were deemed to be viable in astrophysical environments: numbers 1 , 2, 3, 4, 5, 12, 14, 15, 16, 17 and 19 in their Table 1. Our chemical network includes these eleven reactions, with the rates and barriers provided by Roueff et al. (2015). Although these rates appear to be the best currently available, they may have been underestimated for some reactions (Wirström \& Charnley 2018).

\subsubsection{Isotope-selective photodissociation}

Another mechanism to alter isotopolog ratios is isotope-selective photodissocation. $\mathrm{CO}$ and $\mathrm{N}_{2}$ can dissociate only through absorption into a discrete set of narrow far-UV lines (Visser et al. 2009; Li et al. 2013). These lines become saturated for CO and $\mathrm{N}_{2}$ column densities of $\gtrsim 10^{14} \mathrm{~cm}^{-2}$, at which point self-shielding sets in: molecules deep inside a disk or cloud are shielded from dissociating radiation by molecules near the surface.

The rarer isotopologs ${ }^{13} \mathrm{CO}$ and $\mathrm{N}^{15} \mathrm{~N}$ absorb photons at different frequencies than the primary species, and these photons are less strongly shielded. At any depth into a disk or cloud, ${ }^{13} \mathrm{CO}$ and $\mathrm{N}^{15} \mathrm{~N}$ therefore dissociate faster than ${ }^{12} \mathrm{CO}$ and ${ }^{14} \mathrm{~N}_{2}$. Through additional reactions, this affects the ${ }^{14} \mathrm{~N} /{ }^{15} \mathrm{~N}$ ratio in the cyanides (Sect. 3.3.1). Our network includes the $\mathrm{CO}$ and $\mathrm{N}_{2}$ shielding functions from Visser et al. (2009) and Heays et al. (2014). ${ }^{1}$ From the available excitation temperatures and Doppler

\footnotetext{
1 http://home.strw.leidenuniv.nl/ ewine/photo
}

widths, the best choices are $20 \mathrm{~K}$ and $0.30 \mathrm{~km} \mathrm{~s}^{-1}$ for $\mathrm{CO}$ and $30 \mathrm{~K}$ and $0.13 \mathrm{~km} \mathrm{~s}^{-1}$ for $\mathrm{N}_{2}$. These data files include the effects of shielding by $\mathrm{H}$ and $\mathrm{H}_{2}$, though our models show that mutual shielding is not important for nitrogen isotope fractionation in disks.

For a given point in the disk, DALI computes the shielding functions both radially towards the star and vertically towards the disk surface. The photodissociation rate is set by the direction that provides the smaller amount of shielding. The same 1+1D approximation was used by Miotello et al. (2014).

\section{Results}

We present the key characteristics of the nitrogen isotope chemistry for a fiducial disk model of $10^{-3} M_{\odot}$ with $90 \%$ large grains and a scale height angle exponent of $\psi=0.2$. The disk is illuminated by a T Tauri stellar spectrum with a UV excess for an accretion rate of $10^{-8} M_{\odot} \mathrm{yr}^{-1}$, providing an FUV luminosity of $0.018 L_{\odot}$ between 6 and $13.6 \mathrm{eV}$. The elemental isotope ratios are 440 for ${ }^{14} \mathrm{~N} /{ }^{15} \mathrm{~N}$ and 69 for ${ }^{12} \mathrm{C} /{ }^{13} \mathrm{C}$. Section 4.2 discusses how the chemistry depends on various model parameters.

\subsection{Physical characteristics}

Figure 2 shows the two-dimensional profiles of the gas density, UV flux, visual extinction, ionization rate, dust temperature and gas temperature. Vertical cuts are plotted in Fig. 3 for three radii, corresponding to the abundance maximum of $\mathrm{HCN}$ in the surface layers $(R=14 \mathrm{au})$, the abundance maximum of $\mathrm{CN}(57 \mathrm{au})$ and the strongest $\mathrm{N}$ isotope fractionation in HCN (117 au).

The UV flux in both figures is plotted in units of the mean interstellar radiation field $\left(G_{0}\right.$; Habing 1968) and includes effects of geometrical dilution and dust attenuation, as computed through the full 2D continuum radiative transfer. Due to scattered stellar light, the midplane UV flux reaches the equivalent of the interstellar field $\left(G_{0}=1\right)$ at a radius of 95 au. The extinction profile is the result of comparing the actual intensity at each point in the disk to the intensity expected based only on geometrical dilution of the stellar radiation (Visser et al. 2011).

Ionization is controlled by X-rays out to 0.3 au along the midplane, after which the X-ray ionization rate drops below the cosmic ray contribution of $5 \times 10^{-17} \mathrm{~s}^{-1}$. The midplane dust temperature decreases to $100 \mathrm{~K}$ at 1 au and $20 \mathrm{~K}$ at $70 \mathrm{au}$, marking the approximate locations of the $\mathrm{H}_{2} \mathrm{O}$ and $\mathrm{CO}$ snowlines.

The bottom right panel of Fig. 3 shows the photodissociation rates of $\mathrm{N}^{15} \mathrm{~N}$ (thinner lines) and $\mathrm{N}_{2}$ (thicker lines). Self-shielding of $\mathrm{N}_{2}$ is important below $z / R \approx 0.25$ (where $A_{\mathrm{V}} \approx 0.5$ ) and results in an order-of-magnitude reduction in the photodissociation rate relative to $\mathrm{N}^{15} \mathrm{~N}$. The overall decrease of the photodissociation rates from the disk surface down to the midplane is due to extinction by dust. Shielding of $\mathrm{N}_{2}$ and $\mathrm{N}^{15} \mathrm{~N}$ by $\mathrm{H}$ or $\mathrm{H}_{2}$ is negligible.

\subsection{Cyanide abundances and morphologies}

The abundance profiles for $\mathrm{N}_{2}, \mathrm{~N}, \mathrm{HCN}, \mathrm{HCN}$ ice, $\mathrm{HNC}$ and $\mathrm{CN}$ at $1 \mathrm{Myr}$ in the fiducial model are plotted in Fig. 4 and the corresponding vertical cuts appear in Fig. 5. Across the entire disk, the dominant forms of nitrogen are $\mathrm{N}_{2}(47 \%), \mathrm{NH}_{3}$ ice $(30 \%), \mathrm{N}$ $(8 \%), \mathrm{N}_{2}$ ice (7\%) and $\mathrm{NO}$ ice $(6 \%)$. $\mathrm{HCN}$ ice accounts for $1 \%$ of all nitrogen and gas-phase $\mathrm{HCN}$ for only $0.08 \%$. At the inner edge, however, $\mathrm{HCN}$ is the second-most abundant N-bearing species $(30 \%$ for $R<0.2 \mathrm{au})$. 
R. Visser et al.: Nitrogen isotope fractionation in protoplanetary disks
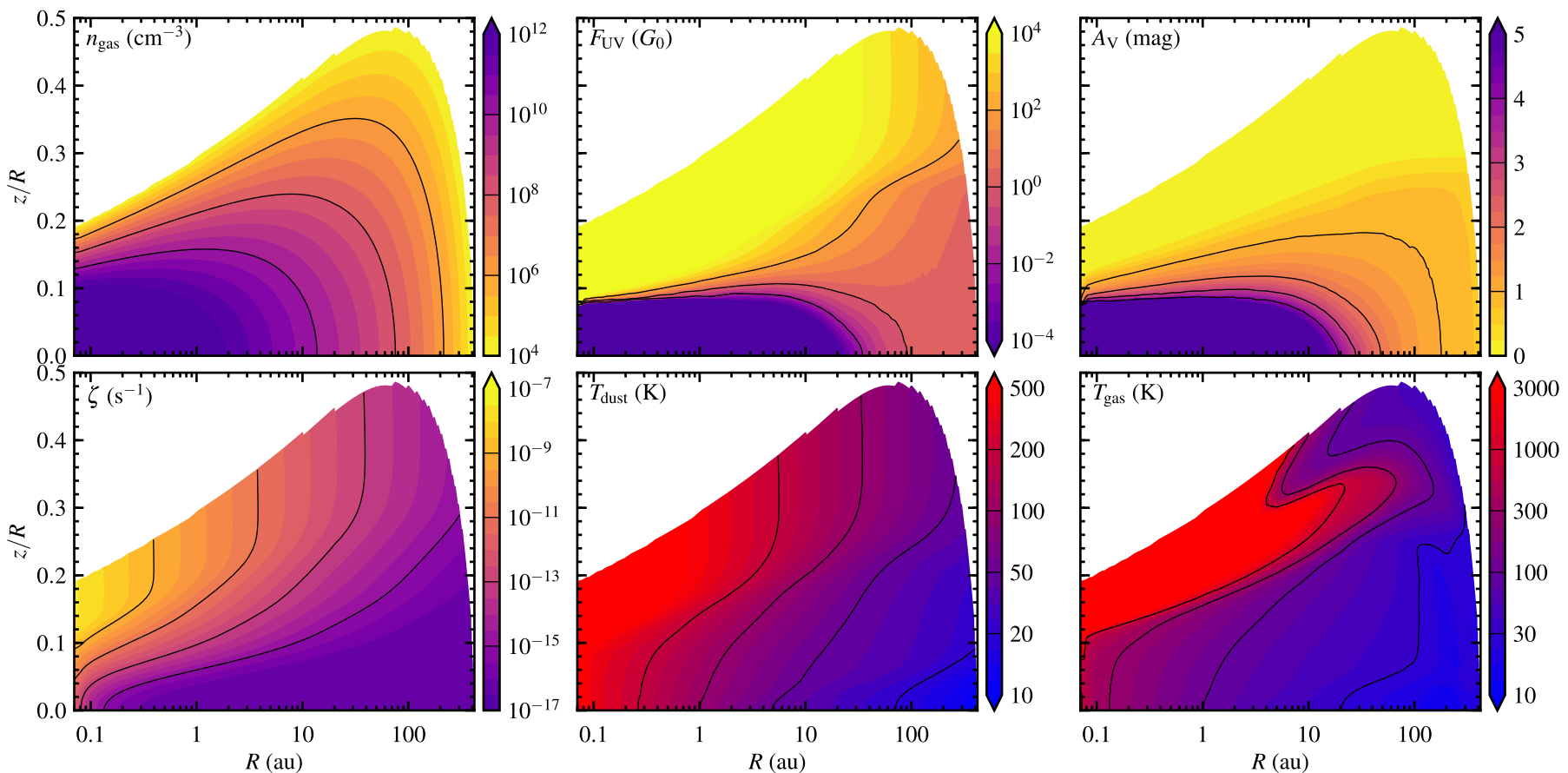

Fig. 2. Gas density, UV flux, visual extinction, ionization rate (sum of X-ray and cosmic ray contributions), dust temperature and gas temperature for a $10^{-3} M_{\odot}$ disk with $90 \%$ large grains, $\chi=0.2$ and $\psi=0.2$, illuminated by a T Tauri stellar spectrum with a UV excess for $10^{-8} M_{\odot} \mathrm{yr}^{-1}$. The $F_{\mathrm{Uv}}$ plot accounts for extinction. All panels are truncated at the $10^{4} \mathrm{~cm}^{-3}$ density contour.
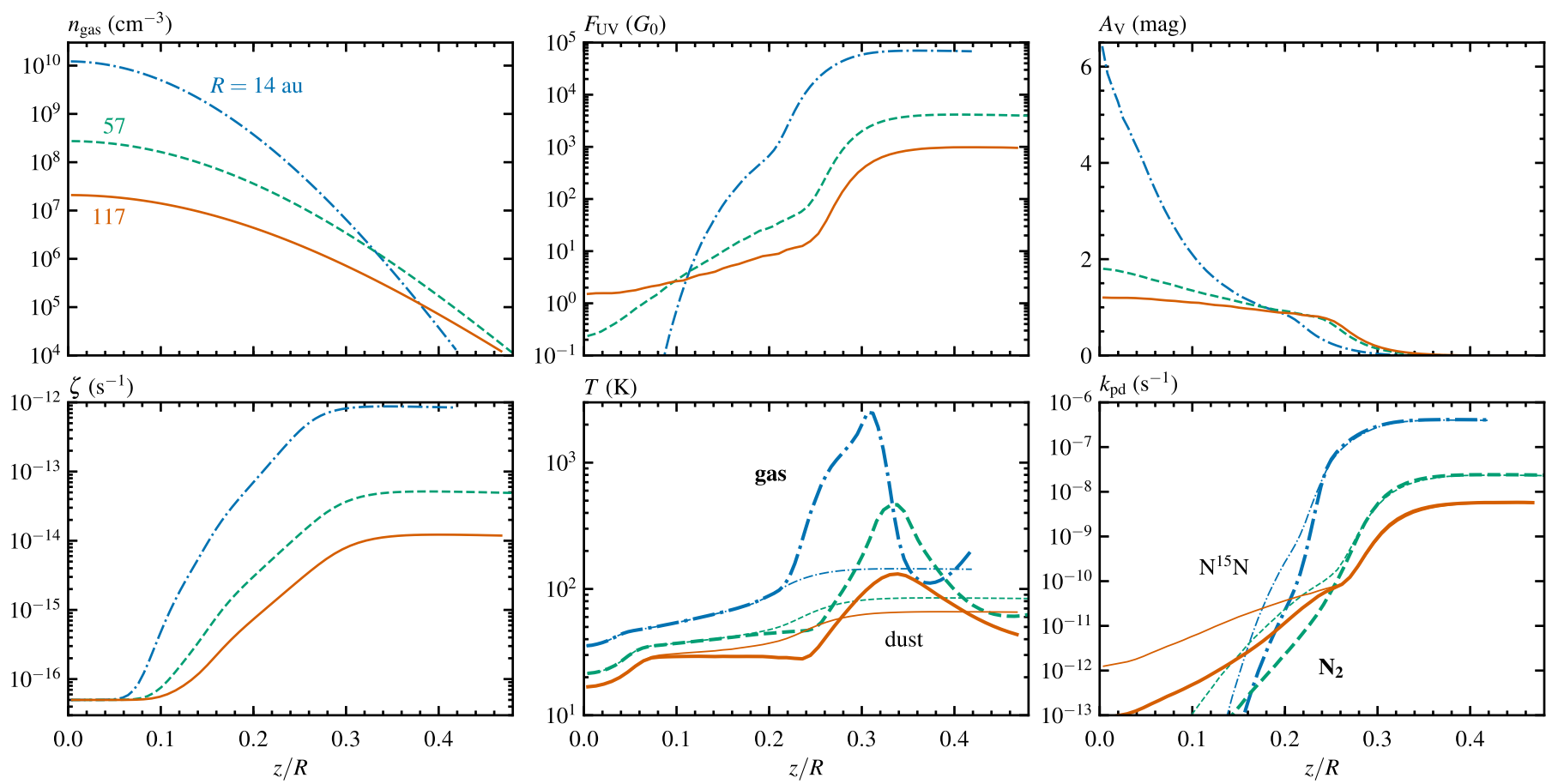

Fig. 3. Vertical cuts corresponding to Fig. 2. Bottom center panel: dust temperatures as thinner lines and gas temperatures as thicker lines. Bottom right panel: photodissociation rate of $\mathrm{N}^{15} \mathrm{~N}$ as thinner lines and that of $\mathrm{N}_{2}$ as thicker lines.

The cyanide morphologies from Fig. 4 are qualitatively similar to those seen in other models (e.g., Aikawa et al. 2002; Markwick et al. 2002; Jonkheid et al. 2007; Agúndez et al. 2008; Woods \& Willacy 2009; Walsh et al. 2010; Fogel et al. 2011; Semenov \& Wiebe 2011; Cleeves et al. 2011; Podio et al. 2014). The high HCN abundance in the inner disk is observed at near- and mid-infrared wavelengths (Lahuis et al. 2006; Gibb et al. 2007; Carr \& Najita 2008; Salyk et al. 2008, 2011;
Mandell et al. 2012), and the colder cyanides in the surface and outer disk are seen with millimeter and submillimeter telescopes (Dutrey et al. 1997; Thi et al. 2004; Salter et al. 2011; Graninger et al. 2015; Guzmán et al. 2015, 2017; Teague et al. 2016; Hily-Blant et al. 2017; van Terwisga et al. 2018).

Aside from the high-abundance inner region, $\mathrm{HCN}$ shows a secondary maximum of $3 \times 10^{-8}$ in a thin layer along the disk surface. Near the midplane, HCN is absent from $R=0.4$ to 

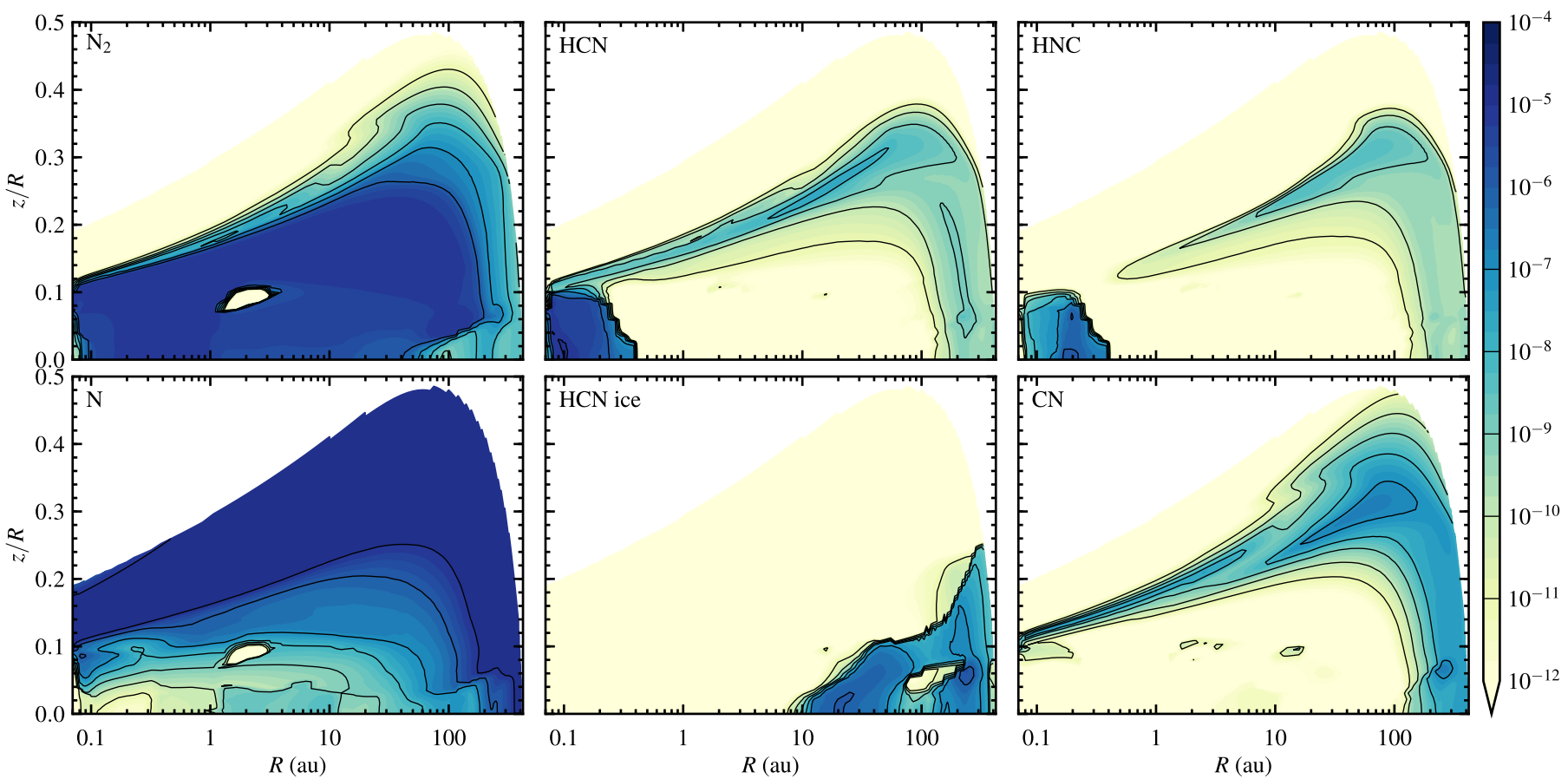

Fig. 4. Abundances at $1 \mathrm{Myr}$ of several N-bearing molecules for the same model as in Fig. 2. Values are relative to $n_{\text {gas }} \approx 2 n\left(\mathrm{H}_{2}\right)+n(\mathrm{H})$. Contours are drawn at intervals of a factor of 10 from $10^{-11}$ up to $10^{-5}$.
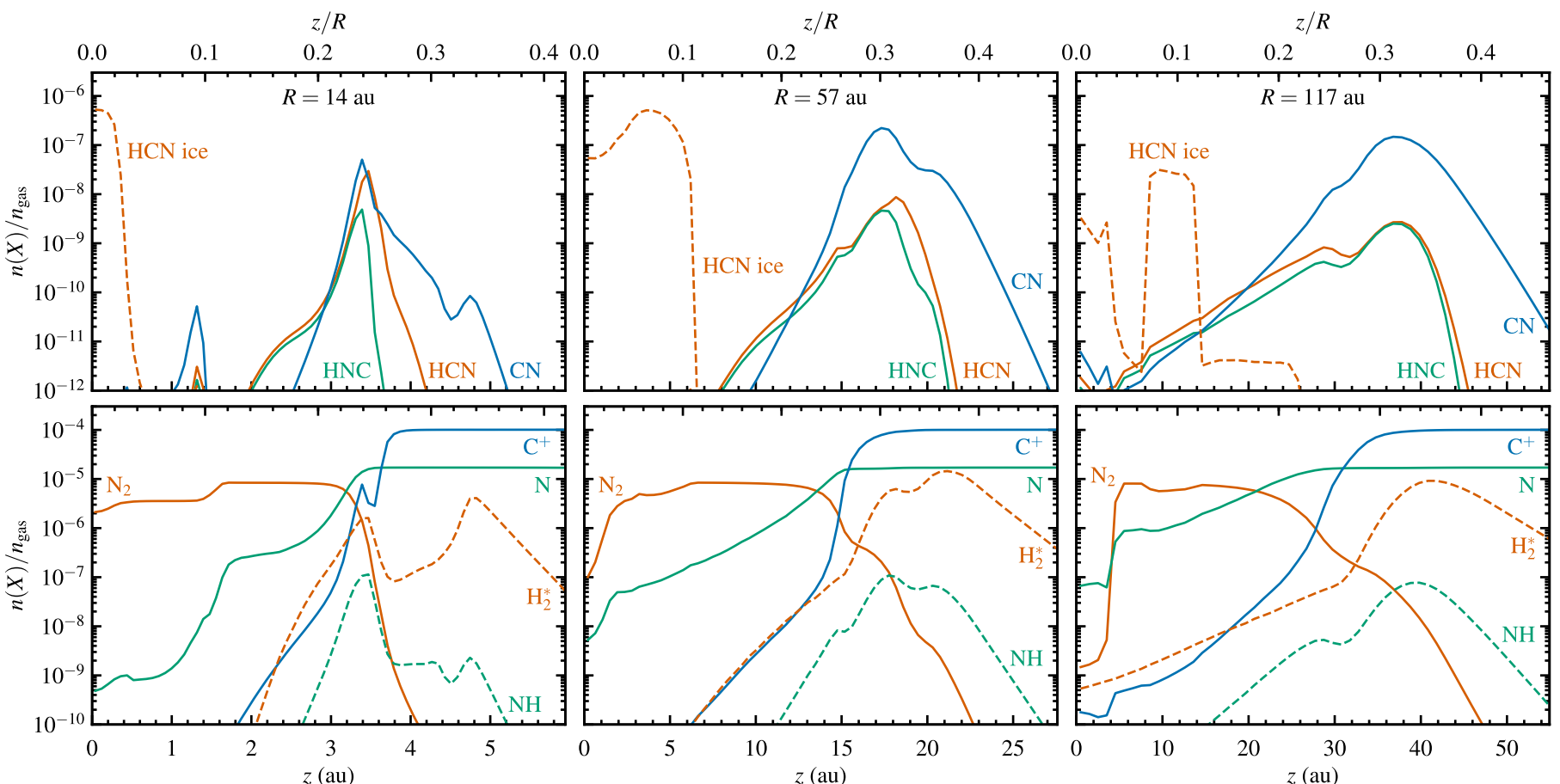

Fig. 5. Vertical cuts corresponding to Fig. 4.

$130 \mathrm{au}$. HCN ice is abundant (up to $1 \times 10^{-6}$ ) outside $8 \mathrm{au}$. HNC follows the same pattern as $\mathrm{HCN}$, but the HNC abundance is systematically lower by about an order of magnitude. For comparison, observations of one T Tauri disk and one Herbig disk showed $\mathrm{HNC} / \mathrm{HCN}$ line intensity ratios of 0.1 to 0.2 (Graninger et al. 2015). CN is confined to the surface layers and outer disk, where it is typically two orders of magnitude more abundant than HCN. CN is more spatially extended than HCN, consistent with ALMA observations (Guzmán et al. 2015). Furthermore, the $\mathrm{CN}$ morphology from Fig. 4 gives rise to a ring of low- $J \mathrm{CN}$ emission, as also observed with ALMA (Teague et al. 2016; van Terwisga et al. 2018). These $\mathrm{CN}$ rings were analyzed in detail by Cazzoletti et al. (2018).

Appendix $\mathrm{C}$ offers a complete breakdown of the various reactions that govern the formation and destruction of $\mathrm{HCN}$, $\mathrm{HNC}$ and $\mathrm{CN}$. The remainder of the current section describes the key physical and chemical aspects of the cyanide morphologies from Figs. 4 and 5.

Inner Disk. HCN is abundant in the inner 0.2 au, fueled by the combination of high temperatures (up to $1300 \mathrm{~K}$ ) 

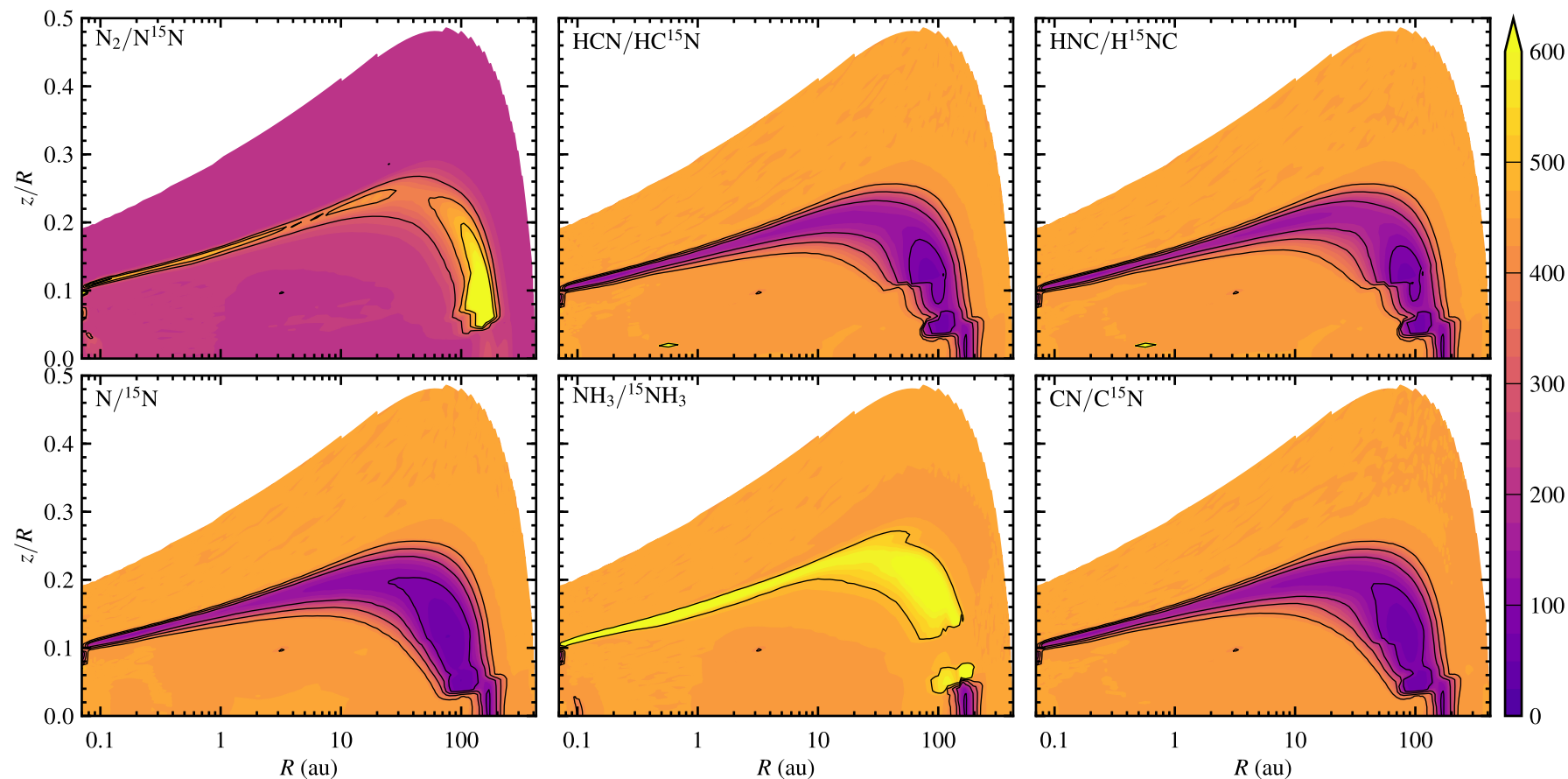

Fig. 6. Nitrogen isotope ratios of several molecules at $1 \mathrm{Myr}$ for the same model as in Fig. 2 . The elemental ${ }^{14} \mathrm{~N} /{ }^{15} \mathrm{~N}$ ratio is 440 . Contours are drawn at ratios of 100, 200, 300, 400 and 500 .

and high ionization rates (up to a few $10^{-11} \mathrm{~s}^{-1}$; Fig. 2). $\mathrm{HCN}$ is formed through all possible pathways starting from $\mathrm{NH}_{3}, \mathrm{~N}$ and $\mathrm{N}_{2}$ (Reactions C.1-C.13). The conversion rate of $\mathrm{HNC}+\mathrm{H} \rightarrow \mathrm{HCN}+\mathrm{H}$ (Reaction C.20) decreases with temperature, so the HNC abundance increases from the inner rim to $0.2 \mathrm{au}$. The $\mathrm{CN}$ abundance is low in this region, because $\mathrm{CN}+\mathrm{H}_{2} \rightarrow \mathrm{HCN}+\mathrm{H}$ (Reaction C.18) drives all $\mathrm{CN}$ to $\mathrm{HCN}$.

Midplane. The midplane temperature drops below $230 \mathrm{~K}$ at $0.2 \mathrm{au}$, disabling the gas-phase formation of water through $\mathrm{O}+\mathrm{H}_{2} \rightarrow \mathrm{OH}$ and $\mathrm{OH}+\mathrm{H}_{2} \rightarrow \mathrm{H}_{2} \mathrm{O}$. Outside 0.2 au, the abundance of atomic $\mathrm{O}$ is high enough to drain the entire cyanide reservoir on a timescale of a few thousand years through $\mathrm{CN}+\mathrm{O} \rightarrow \mathrm{CO}+\mathrm{N}$ (Reaction C.23). The snowlines of $\mathrm{HCN}$ and $\mathrm{HNC}$ lie at $8 \mathrm{au}$ and that of $\mathrm{CN}$ at 16 au. At larger radii, any cyanides formed in the gas freeze onto the dust and are safe from destruction by atomic $\mathrm{O}$. Gas-phase cyanides remain absent along the midplane until $130 \mathrm{au}$, at which point UV-driven chemistry takes over.

Surface. Photodissociation and photoionization rule the surface layers of the disk. The UV field dissociates $\mathrm{N}_{2}$ and $\mathrm{CO}$, and it pumps $\mathrm{H}_{2}$ into a vibrationally excited state. This $\mathrm{H}_{2}^{*}$ reacts with $\mathrm{N}$ to $\mathrm{NH}$, which reacts further with $\mathrm{C}$ or $\mathrm{C}^{+}$ to produce $\mathrm{HCN}, \mathrm{HNC}$ and $\mathrm{CN}$ (Reactions C.3-C.5). Most of the surface is warm enough to overcome the barrier of $960 \mathrm{~K}$ on $\mathrm{CN}+\mathrm{H}_{2} \rightarrow \mathrm{HCN}+\mathrm{H}$ (Reaction C.18), so formation of $\mathrm{HCN}$ from $\mathrm{CN}$ and $\mathrm{H}_{2}$ is faster than photodissociation of $\mathrm{HCN}$ to $\mathrm{CN}$ and $\mathrm{H}$. The two dominant cyanide loss channels are photodissociation of $\mathrm{CN}$ and the reaction of $\mathrm{CN}$ with $\mathrm{O}$.

Outer Disk. Photodissociation and photoionization remain important at intermediate altitudes and in the outer disk, but the UV flux is lower and the gas is colder than in the surface layers. The lower abundance of $\mathrm{H}_{2}^{*}$ slows down production of $\mathrm{CN}$ from N and NH (Reactions C.3-C.5). Production of HCN slows down even more because of the barrier on $\mathrm{CN}+\mathrm{H}_{2} \rightarrow \mathrm{HCN}+\mathrm{H}$ (Reaction C.18).
To highlight the importance of vibrationally excited $\mathrm{H}_{2}$ for the cyanide abundances, consider the vertical cuts in Fig. 5. At each radius, $\mathrm{CN}, \mathrm{HCN}, \mathrm{HNC}$ all peak in a narrow band of altitudes near $z / R$ of 0.2 to 0.3 . When the abundances are high enough, a shoulder or secondary peak appears at $z / R$ of 0.3 to 0.4 . $\mathrm{NH}$ and $\mathrm{H}_{2}^{*}$ have the same dual-peaked profiles as the cyanides. In contrast, the abundances of $\mathrm{N}$ and $\mathrm{C}^{+}$follow an entirely different pattern.

Based on the similar vertical abundance profiles, the chemistry of $\mathrm{H}_{2}^{*}, \mathrm{NH}$ and the cyanides is closely linked. This conclusion is also evident when plotting the abundances as a function of radius at constant $z$ or $z / R$ through the $\mathrm{CN}$ maximum (not shown). The abundance profile of $\mathrm{H}_{2}^{*}$ represents a balance between excitation due to UV pumping and deexcitation due to spontaneous decay and collisions with ground-state $\mathrm{H}$ or $\mathrm{H}_{2}$. At altitudes above the $\mathrm{CN}$ maximum, photodissociation of $\mathrm{H}_{2}$ provides an additional loss channel for $\mathrm{H}_{2}^{*}$.

\subsection{Isotope ratios}

\subsection{1. ${ }^{14} \mathrm{~N} /{ }^{15} \mathrm{~N}$}

Figure 6 shows the nitrogen isotope ratios for $\mathrm{N}_{2}, \mathrm{~N}, \mathrm{HCN}, \mathrm{HNC}$, $\mathrm{CN}$ and $\mathrm{NH}_{3}$ in the fiducial disk model. Vertical cuts at 14, 57 and $117 \mathrm{au}$ appear in Fig. 7. All six species undergo isotope fractionation in a region extending from near the disk surface down to the midplane at 100-200 au.

Molecular nitrogen is depleted in ${ }^{15} \mathrm{~N}$, reaching a peak $\mathrm{N}_{2} / \mathrm{N}^{15} \mathrm{~N}$ ratio of 750 at a radius of 150 au. This value is 3.4 times higher than the primordial $\mathrm{N}_{2} / \mathrm{N}^{15} \mathrm{~N}$ ratio ratio of 220 . Fractionation in $\mathrm{N}_{2}$ is fully driven by isotope-selective photodissociation, which lowers the photodissociation rate of $\mathrm{N}_{2}$ by an order of magnitude compared to $\mathrm{N}^{15} \mathrm{~N}$ (Fig. 3, bottom right). The relative importance of isotope-selective photodissociation and low-temperature isotope exchange reactions is discussed in more detail in Sect. 4.1. 


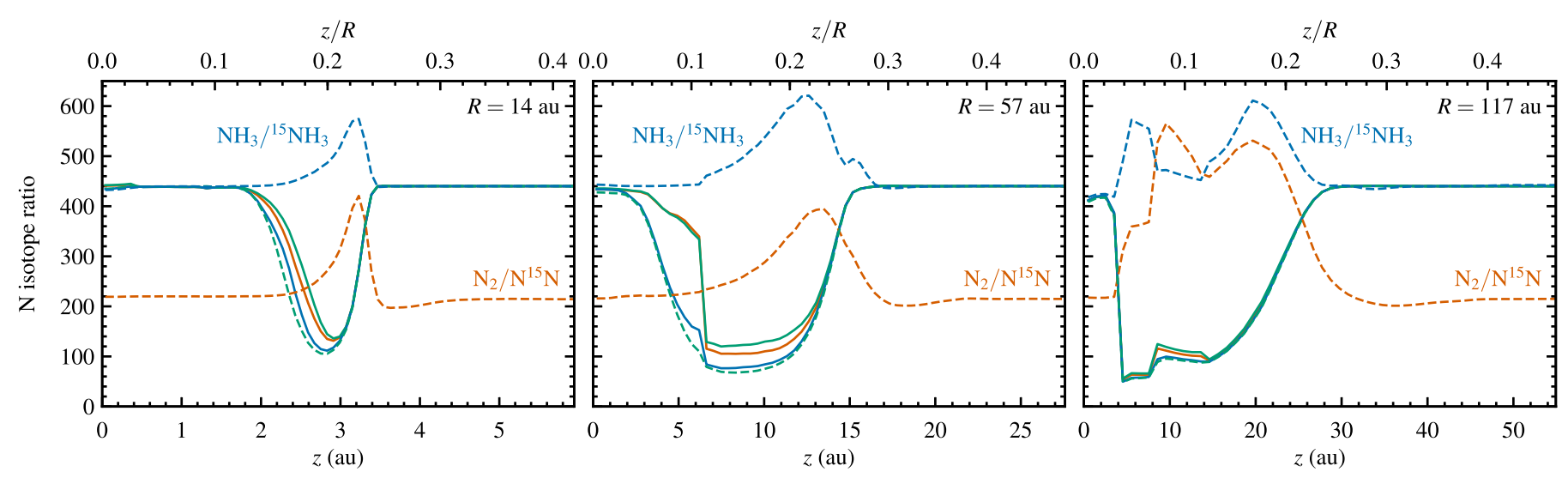

Fig. 7. Vertical cuts corresponding to Fig. 6. The profiles for $\mathrm{N}_{2} / \mathrm{N}^{15} \mathrm{~N}$ and $\mathrm{NH}_{3} /{ }^{15} \mathrm{NH}_{3}$ are labeled. From top to bottom, the remaining profiles are for $\mathrm{HNC} / \mathrm{H}^{15} \mathrm{NC}$ (solid green), $\mathrm{HCN} / \mathrm{HC}^{15} \mathrm{~N}$ (solid orange), $\mathrm{CN} / \mathrm{C}^{15} \mathrm{~N}$ (solid blue) and $\mathrm{N} /{ }^{15} \mathrm{~N}$ (dashed green).

The isotope-selective photodissociation of $\mathrm{N}_{2}$ leads to strong fractionation in atomic $\mathrm{N}$ in the bottom left panel of Fig. 6 . The $\mathrm{N} /{ }^{15} \mathrm{~N}$ ratio reaches a minimum of 48 at $R=82 \mathrm{au}, 9.2$ times lower than the initial ratio of 440 . Formation of $\mathrm{CN}, \mathrm{HCN}$ and HNC generally begins with atomic N (Appendix C), so the level of fractionation in the three cyanides closely follows that of N/ ${ }^{15} \mathrm{~N}$ (Fig. 7).

Lastly, ammonia shows both ${ }^{15} \mathrm{~N}$ enhancement and depletion. The enhancement is strongest at the midplane around 170 au, with an $\mathrm{NH}_{3} /{ }^{15} \mathrm{NH}_{3}$ ratio down to 94 . Depletion of ${ }^{15} \mathrm{~N}$ is seen in a layer from $z / R=0.10$ at the inner edge to $z / R=0.22$ at 40 au and curving down to $z / R=0.06$ near $150 \mathrm{au}$. The highest $\mathrm{NH}_{3} /{ }^{15} \mathrm{NH}_{3}$ ratio in the model is 800 , corresponding to ${ }^{15} \mathrm{~N}$ depletion by a factor of 1.8 .

The dual behavior of the $\mathrm{NH}_{3} /{ }^{15} \mathrm{NH}_{3}$ ratio is due to different sources of the nitrogen atom in ammonia. Throughout the disk, $\mathrm{NH}_{3}$ is formed by successive hydrogenation of $\mathrm{NH}^{+}$and dissociative recombination of the resulting $\mathrm{NH}_{4}^{+}$. The difference lies in the origin of $\mathrm{NH}^{+}$. In the region of reduced $\mathrm{NH}_{3} /{ }^{15} \mathrm{NH}_{3}$ (i.e., ${ }^{15} \mathrm{~N}$ enhancement), the primary formation pathway of $\mathrm{NH}^{+}$ is photoionization of $\mathrm{NH}$. In turn, $\mathrm{NH}$ arises from atomic $\mathrm{N}$ and vibrationally excited $\mathrm{H}_{2}$ via $\mathrm{N}+\mathrm{H}_{2}^{*} \rightarrow \mathrm{NH}+\mathrm{H}$ (Reaction C.3). Hence, the isotope fractionation in $\mathrm{NH}_{3}$ follows that of atomic $\mathrm{N}$. In the other region, where ammonia is depleted in ${ }^{15} \mathrm{~N}, \mathrm{NH}^{+}$ is formed in two steps: $\mathrm{N}_{2}$ reacts with $\mathrm{He}^{+}$to $\mathrm{N}$ and $\mathrm{N}^{+}$, and the latter reacts with $\mathrm{H}_{2}$ to $\mathrm{NH}^{+}$. Since $\mathrm{NH}_{3}$ is ultimately formed from $\mathrm{N}_{2}$ in these two regions, the $\mathrm{NH}_{3} /{ }^{15} \mathrm{NH}_{3}$ ratio follows the $\mathrm{N}_{2} / \mathrm{N}^{15} \mathrm{~N}$ ratio.

\subsection{2. ${ }^{12} \mathrm{C} /{ }^{13} \mathrm{C}$}

The low- $J$ rotational lines of $\mathrm{HCN}$ are optically thick in most circumstellar disks. The ${ }^{14} \mathrm{~N} /{ }^{15} \mathrm{~N}$ ratio is therefore usually derived from $\mathrm{H}^{13} \mathrm{CN}$ and $\mathrm{HC}^{15} \mathrm{~N}$, assuming a ${ }^{12} \mathrm{C} /{ }^{13} \mathrm{C}$ ratio of 70 (Hily-Blant et al. 2013; Wampfler et al. 2014; Guzmán et al. 2015, 2017). Our model includes ${ }^{13} \mathrm{C}$ in order to test if the assumption of a constant $\mathrm{HCN} / \mathrm{H}^{13} \mathrm{CN}$ ratio is correct.

Figure 8 shows the carbon isotope ratios for $\mathrm{CO}, \mathrm{C}, \mathrm{C}^{+}, \mathrm{HCN}$, $\mathrm{HNC}$ and $\mathrm{CN}$ in the fiducial disk model, and the corresponding vertical cuts appear in Fig. 9. The nitrogen isotope patterns in Fig. 6 are relatively simple, because isotope-selective photodissociation is the only active fractionation mechanism. For carbon, both selective photodissociation and low-temperature isotope exchange are important in the overall isotope balance. Hence, the fractionation patterns of carbon are more complex than those of nitrogen.
Carbon fractionation is largely controlled by $\mathrm{CO}$, the most abundant carbon species. At the outer edge of the disk, the column density of $\mathrm{CO}$ is insufficient to provide self-shielding against the interstellar radiation field or the scattered stellar UV light. Because the gas is cold $(<30 \mathrm{~K})$, the isotope exchange reaction ${ }^{13} \mathrm{C}^{+}+\mathrm{CO} \rightleftarrows \mathrm{C}^{+}+{ }^{13} \mathrm{CO}+35 \mathrm{~K}$ is faster in the forward direction than backwards. This leads to an enhancement in ${ }^{13} \mathrm{CO}$, visible as $\mathrm{CO} /{ }^{13} \mathrm{CO}$ ratios down to 12 in the top left panel of Fig. 8.

Moving in from the outer edge, ${ }^{12} \mathrm{CO}$ becomes self-shielded once it builds up a column density of $\sim 10^{14} \mathrm{~cm}^{-2}$. From here on in, ${ }^{13} \mathrm{CO}$ photodissociates faster than ${ }^{12} \mathrm{CO}$. The gas temperature increases at the same time (from $\sim 20$ to $\sim 30 \mathrm{~K}$ ), reducing the effect of the low-temperature exchange process. The net result is an extended region with a minor increase in the $\mathrm{CO} /{ }^{13} \mathrm{CO}$ ratio of up to 80 and a smaller spot near the midplane at 220 au with $\mathrm{CO} /{ }^{13} \mathrm{CO}$ up to 170 . The region of modest ${ }^{13} \mathrm{CO}$ depletion runs from $z / R=0.04$ at $R=220$ au up and in to $z / R=0.26$ at $100 \mathrm{au}$, and continues all along the disk surface to $z / R=0.1$ at the inner edge.

The fractionation pattern for atomic $\mathrm{C}$ is opposite to that of $\mathrm{CO}$, not only spatially, but also in magnitude. The region of strong ${ }^{13} \mathrm{CO}$ enhancement at the outer edge corresponds to moderate depletion (up to $40 \%$ ) in atomic ${ }^{13} \mathrm{C}$, while the extended region of modest ${ }^{13} \mathrm{CO}$ depletion shows strong enhancement of ${ }^{13} \mathrm{C}$ (up to a factor of 9). In all cases, photodissociation of $\mathrm{CO}$ and ${ }^{13} \mathrm{CO}$ is the major source of $\mathrm{C}$ and ${ }^{13} \mathrm{C}$. The outer edge of the disk is where $\mathrm{C}$ and $\mathrm{C}^{+}$take over from $\mathrm{CO}$ as the dominant carbon carriers, so even a large change in the $\mathrm{CO} /{ }^{13} \mathrm{CO}$ ratio has little effect on the isotope ratio of the much more abundant atomic species. The reverse effect is seen away from the outer edge, where most carbon is locked up in CO: a small change in the photodissociation rates of $\mathrm{CO}$ and ${ }^{13} \mathrm{CO}$ gets amplified into a large difference in the $\mathrm{C} /{ }^{13}$ Cabundance ratio.

Ionized carbon shows no depletion at the very outer edge of disk, where its high abundance leaves it unaffected by the fractionation of $\mathrm{CO}$. The bulk of the disk has an elevated $\mathrm{C}^{+} /{ }^{13} \mathrm{C}^{+}$ratio (up to 920) and that ratio generally increases with decreasing gas temperature. The responsible mechanism is the aforementioned reaction of ${ }^{13} \mathrm{C}^{+}$with $\mathrm{CO}$. Even though ${ }^{13} \mathrm{C}^{+}$is formed from a reservoir of enhanced ${ }^{13} \mathrm{C}$, the exchange with $\mathrm{CO}$ has a larger effect and causes strong depletion of ${ }^{13} \mathrm{C}^{+}$. However, there is one region with ${ }^{13} \mathrm{C}^{+}$enhancement: a thin layer along the disk surface, from $R=0.1$ to $10 \mathrm{au}$. This is at the $\mathrm{CO} / \mathrm{C} / \mathrm{C}^{+}$ transition, where the gas temperatures of a few $100 \mathrm{~K}$ are too 

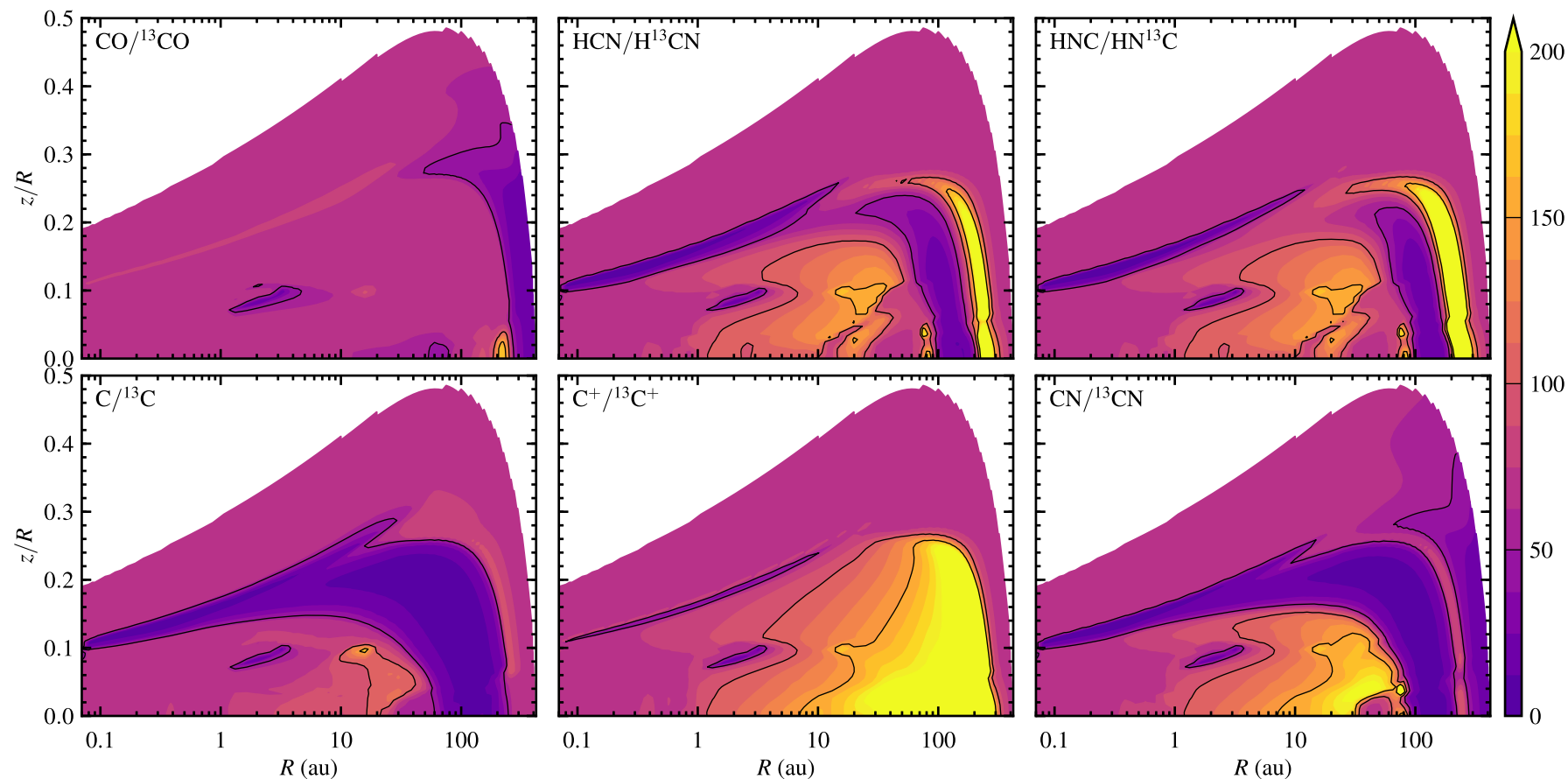

Fig. 8. Carbon isotope ratios of several molecules at $1 \mathrm{Myr}$ for the same model as in Fig. 2. The elemental ${ }^{12} \mathrm{C} /{ }^{13} \mathrm{C}$ ratio is 69 . Contours are drawn at ratios of 50, 100 and 150 .

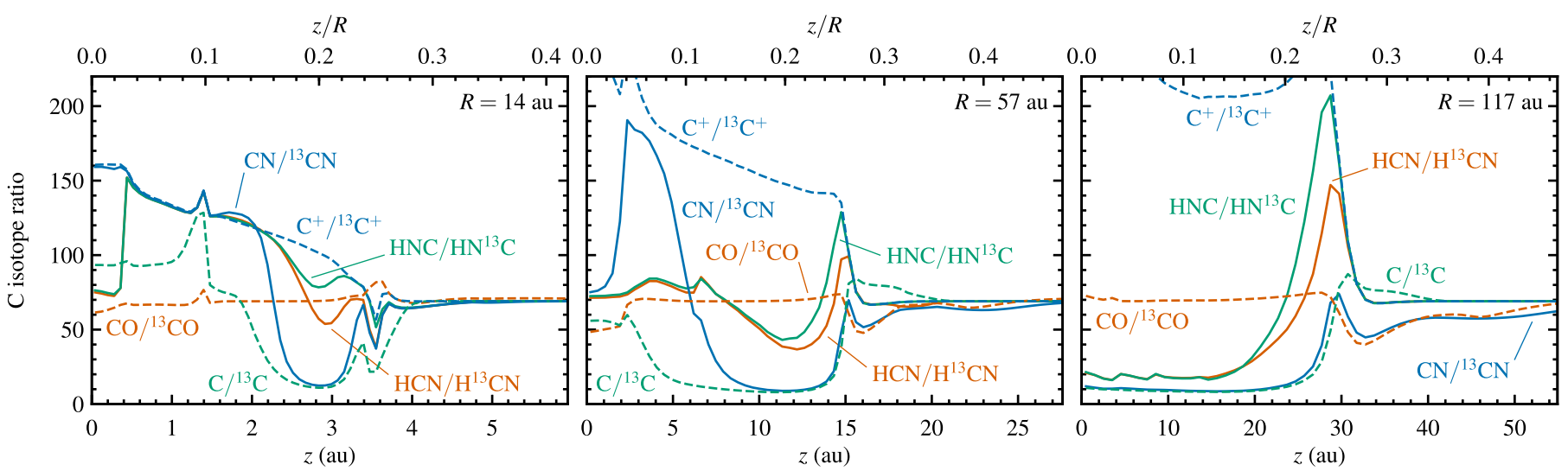

Fig. 9. Vertical cuts corresponding to Fig. 8.

high for the low-temperature exchange mechanism to still be active. Instead, the ${ }^{13} \mathrm{C} /{ }^{13} \mathrm{C}^{+}$ratio is set by the isotope-selective photodissociation of $\mathrm{CO}$.

At the outer edge of the disk $(R>200 \mathrm{au}), \mathrm{CN}$ is closely linked to and follows the fractionation of CO. Photodissociation and ionization convert $\mathrm{CO}$ to $\mathrm{C}^{+}$, which rapidly reacts with $\mathrm{NH}$. The product $\mathrm{CN}^{+}$then undergoes charge exchange with $\mathrm{H}$ to form $\mathrm{CN}$. The $\mathrm{CO}-\mathrm{CN}$ loop is closed by the reaction between $\mathrm{CN}$ and $\mathrm{O}$ to form $\mathrm{CO}$ and $\mathrm{N}$. $\mathrm{HCN}$ and $\mathrm{HNC}$ are about four orders of magnitude less abundant than $\mathrm{CN}$ and are not closely linked to it. Instead, HCN and HNC are mostly formed by the dissociative recombination of $\mathrm{HCNH}^{+}$, which in turn arises from $\mathrm{C}^{+}$reacting with $\mathrm{NH}_{3}$. The ratios of $\mathrm{HCN} / \mathrm{H}^{13} \mathrm{CN}$ and $\mathrm{HNC} / \mathrm{H}^{13} \mathrm{NC}$ in this part of the disk follow $\mathrm{C}^{+} /{ }^{13} \mathrm{C}^{+}$, i.e., no fractionation at the very outer edge and ${ }^{13} \mathrm{C}$ depletion around $R=200-300$ au.

Moving in to around $100 \mathrm{au}$, all three cyanide species show ${ }^{13} \mathrm{C}$ enhancements of up to a factor of 6 . Due to the lower abundance of $\mathrm{C}^{+}$, formation of $\mathrm{CN}$ is now dominated by the reaction of $\mathrm{C}$ with $\mathrm{NH}$ or NO. Neutral-neutral chemistry also controls the abundance $\mathrm{HCN}$, in particular through the reaction of $\mathrm{CH}$ with $\mathrm{NO}$. Charge exchange reactions through the intermediate $\mathrm{HCNH}^{+}$allow both $\mathrm{CN}$ and $\mathrm{HCN}$ to be converted to $\mathrm{HNC}$. $\mathrm{CH}$ is formed from $\mathrm{C}$ and $\mathrm{H}_{2}^{*}$, so the carbon fractionation in all three cyanides follows the fractionation of atomic $\mathrm{C}$. The same coupling between $\mathrm{C}$ and the cyanides is also seen in the surface layers.

In order to compare with observations, column density ratios are more useful than abundance ratios. Figure 10 shows the ratio of $N(\mathrm{HCN})$ over $N\left(\mathrm{H}^{13} \mathrm{CN}\right)$ as a function of radius, ranging from a global minimum of 15 at 1 au and a local minimum of 47 at $130 \mathrm{au}$ to a maximum of 200 at $240 \mathrm{au}$. The observations of Guzmán et al. (2017) probed $\mathrm{H}^{13} \mathrm{CN}$ and $\mathrm{HC}^{15} \mathrm{~N}$ out to radii of $100 \mathrm{au}$ with a beam size of about $60 \mathrm{au}$. Under these conditions, Fig. 10 essentially shows a constant ${ }^{12} \mathrm{C} /{ }^{13} \mathrm{C}$ ratio in $\mathrm{HCN}$. The variations in the inner 100 au are smaller than the uncertainty of $30 \%$ assumed by Guzmán et al. to convert $\mathrm{H}^{13} \mathrm{CN}$ column densities to $\mathrm{HCN}$ column densities. If future observations probe gas out to larger radii, the assumption of a constant ${ }^{12} \mathrm{C} /{ }^{13} \mathrm{C}$ ratio will need to be reevaluated. 


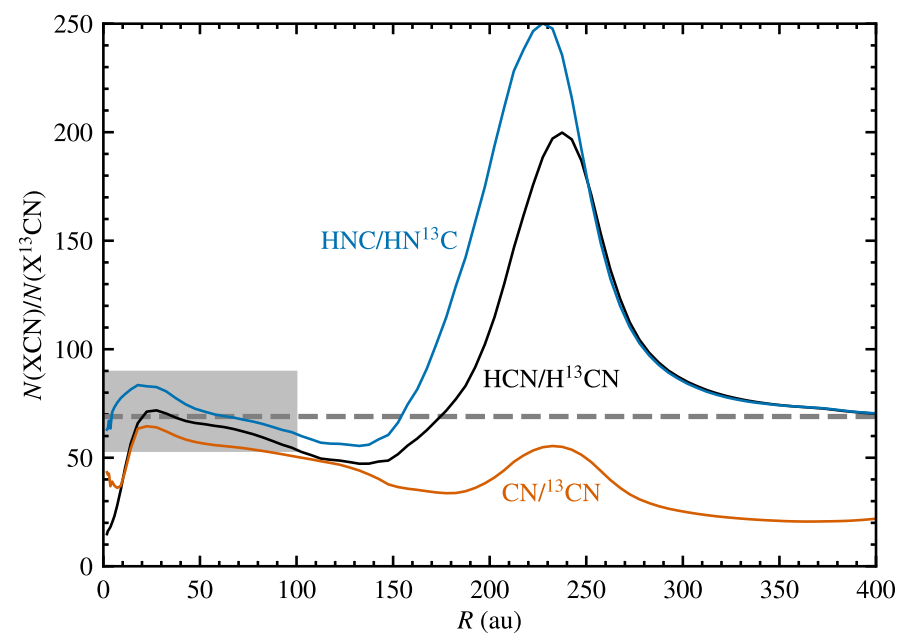

Fig. 10. Column density ratios of ${ }^{12} \mathrm{C} /{ }^{13} \mathrm{C}$ in $\mathrm{HCN}, \mathrm{HNC}$ and $\mathrm{CN}$ at $1 \mathrm{Myr}$ as a function of radius in the fiducial disk model. The dashed gray line marks the elemental ${ }^{12} \mathrm{C} /{ }^{13} \mathrm{C}$ ratio of 69 . The shaded region indicates the $30 \%$ uncertainty assumed by Guzmán et al. (2017), whose observations probed material out to $100 \mathrm{au}$.

\section{Discussion}

\subsection{Dominant isotope fractionation mechanism and comparison with observations}

We reran the fiducial model with either the low-temperature isotope exchange reactions turned off or with the self-shielding of $\mathrm{N}_{2}$ turned off, and once more with both mechanisms turned off. The left and center panels of Fig. 11 show the effects of enabling only one fractionation mechanism at a time. Starting from the original ratios, with both mechanisms switched on (Fig. 6, top center), the ratios do not change when the lowtemperature exchange reactions are disabled (Fig. 11, left). The ratios do change substantially when self-shielding is turned off (Fig. 11, middle), indicating that self-shielding of $\mathrm{N}_{2}$ is the dominant fractionation mechanism in our models.

Another way to demonstrate the importance of self-shielding over low- $T$ fractionation is to plot column density ratios (Fig. 12). The curves for "both mechanisms off" and "selfshielding off, low- $T$ on" fall on top of each other, as do the curves for "both on" and "self-shielding on, low- $T$ off". Hence, the column density ratios are completely unaffected by whether or not the low-temperature pathways are active.

As noted by Wirström \& Charnley (2018), the reaction rates for some of the low- $T$ exchange reactions may have been underestimated by Roueff et al. (2015). Given that the bulk of the disk is warmer than $20 \mathrm{~K}$, it appears that our conclusion regarding the dominant fractionation mechanism is robust even against order-of-magnitude variations in the exchange rates.

The HCN/HC ${ }^{15} \mathrm{~N}$ abundance and column density ratios at a chemical age of $1 \mathrm{Myr}$ do not depend on the initial ratios. Our fiducial model starts with $n(\mathrm{HCN}) / n\left(\mathrm{HC}^{15} \mathrm{~N}\right)=440$. We ran test models starting with ratios of 300 and 150 , while keeping the elemental ${ }^{14} \mathrm{~N} /{ }^{15} \mathrm{~N}$ ratio at 440 . In the absence of self-shielding, both models end up with the upper column density ratio profiles from Fig. 12. With self-shielding turned on, the column density ratios match the lower curves. Hence, inheritance alone is not sufficient to explain the isotopolog ratios observed in disks. Instead, the observations require active fractionation powered by self-shielding of $\mathrm{N}_{2}$.
With self-shielding active, the fiducial model produces abundance ratios from 55 to 440 for both $\mathrm{HCN} / \mathrm{HC}^{15} \mathrm{~N}$ and $\mathrm{CN} / \mathrm{C}^{15} \mathrm{~N}$. Fractionation is strongest at radii from 50 to 200 au and altitudes from 40 au down to the midplane. No nitrogen isotope fractionation is seen at the midplane inside of $100 \mathrm{au}$, where comets and other solid bodies would be formed. Nonetheless, solar system comets show strong and uniform fractionation in both $\mathrm{HCN}$ and $\mathrm{CN}$ (average ${ }^{14} \mathrm{~N} /{ }^{15} \mathrm{~N}$ ratios of $140-150$; Jehin et al. 2009; Bockelée-Morvan et al. 2015; Hily-Blant et al. 2017). A combination of radial and vertical mixing can bring highly fractionated material into the comet-forming zone. Such mixing is also part of the theory of how isotope-selective photodissociation of $\mathrm{CO}$ resulted in the oxygen isotope ratios observed in meteorites (Lyons \& Young 2005).

The $\mathrm{HCN} / \mathrm{HC}^{15} \mathrm{~N}$ column density ratio in the fiducial model varies between 270 and 440 in the inner $250 \mathrm{au}$. The lowest values appear between 100 and $200 \mathrm{au}$. The $\mathrm{H}^{13} \mathrm{CN}$ and $\mathrm{HC}^{15} \mathrm{~N}$ observations of six disks by Guzmán et al. (2017) probed gas at radii up to $100 \mathrm{au}$. The inferred $\mathrm{HCN} / \mathrm{HC}^{15} \mathrm{~N}$ ratios range from $83 \pm 32$ to $156 \pm 71$ and are shown in Fig. 12 as shaded gray regions. Ignoring the uncertainties, the average ratio from the observed sample is a factor of 2 lower than the lowest column densities in the model and a factor of 3 lower than the average model ratio inside 100 au. Including uncertainties, the models and observations agree to better than a factor of 2 .

With model $\mathrm{HCN} / \mathrm{HC}^{15} \mathrm{~N}$ abundance ratios down to 55 , the discrepancy in column density ratios is not due to insufficient levels of fractionation as such. Rather, the regions with strong fractionation do not coincide with the regions that contribute most to the column densities of $\mathrm{HCN}$ and $\mathrm{HC}^{15} \mathrm{~N}$. Various trial runs have shown that the $\mathrm{HCN}$ morphology is sensitive to the treatment of vibrationally excited $\mathrm{H}_{2}$. The current single-level approximation (Appendix A) may not be appropriate for the cyanide chemistry, and a more detailed multi-level approach could be considered in the future. Furthermore, a proper comparison between observations and models requires full radiative transfer and excitation to compare actual line intensities. Guzmán et al. (2017) assumed local thermodynamic equilibrium, a single excitation temperature of $15 \mathrm{~K}$ and optically thin emission. These assumptions remain to be validated in future studies.

Throughout the disk, the abundance ratios of $\mathrm{CN} / \mathrm{C}^{15} \mathrm{~N}$ are very similar to those of $\mathrm{HCN} / \mathrm{HC}^{15} \mathrm{~N}$ (Fig. 7). In terms of column densities, however, $\mathrm{CN}$ shows less isotope fractionation than $\mathrm{HCN}$. The $N(\mathrm{CN}) / N\left(\mathrm{C}^{15} \mathrm{~N}\right)$ ratio in the fiducial model reaches a minimum of 310 at a radius of 180 au and shows an average of 400 in the inner 70 au. Hily-Blant et al. (2017) inferred a $\mathrm{CN} / \mathrm{C}^{15} \mathrm{~N}$ ratio of $323 \pm 30$ on the same spatial scales in the disk around the T Tauri star TW Hya. Future observations will hopefully tell whether this ratio is unique to this source or representative of circumstellar disks in general $^{2}$.

\subsection{Effect of disk parameters}

The results presented so far were for one particular disk model, with a gas mass of $10^{-3} M_{\odot}, 90 \%$ large grains and a scale height angle exponent of $\psi=0.2$ (Sect. 2.1). The stellar radiation field was that of a $4000 \mathrm{~K}$ blackbody (representing a T Tauri star) with a UV excess for an accretion rate of $10^{-8} M_{\odot} \mathrm{yr}^{-1}$. The current subsection discusses how changing these parameters affects the fractionation of the nitrogen isotopes. All models herein include self-shielding of $\mathrm{N}_{2}$ and low-temperature isotope exchange reactions.

\footnotetext{
2 See the Note added in proof after the Acknowledgements.
} 

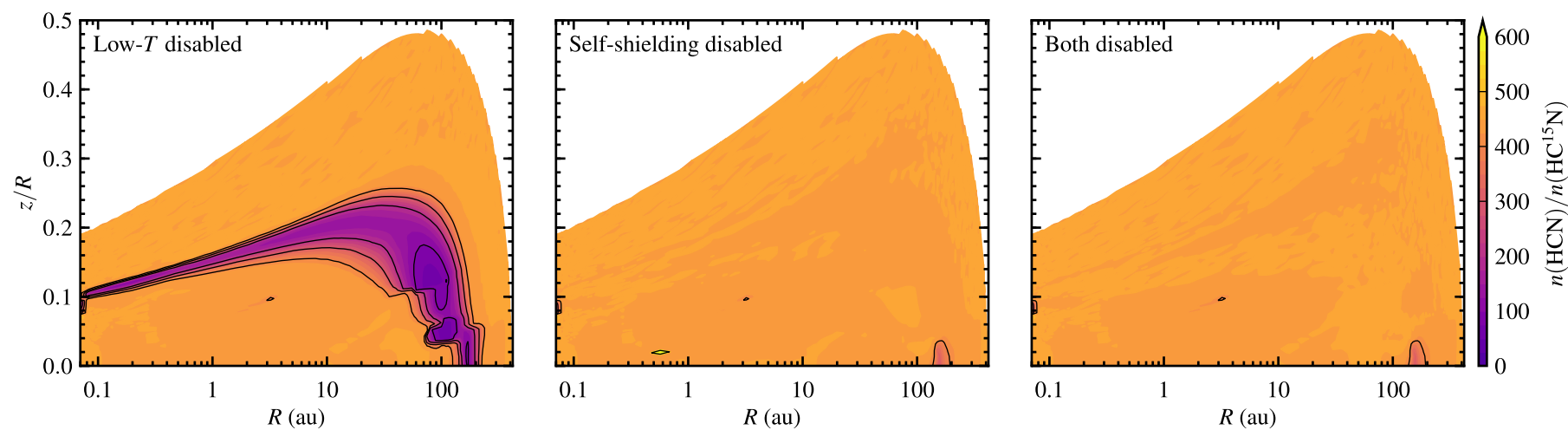

Fig. 11. Abundance ratios of $\mathrm{HCN}$ over $\mathrm{HC}^{15} \mathrm{~N}$ at $1 \mathrm{Myr}$ in the fiducial disk model for three variations of the chemical network: with lowtemperature isotope exchange reactions disabled (left), with self-shielding of $\mathrm{N}_{2}$ disabled (center), or with both fractionation mechanisms disabled (right). The ratios obtained with both mechanisms active are shown in the top center panel of Fig. 6. Contours are drawn at ratios of 100, 200, 300, 400 and 500 .

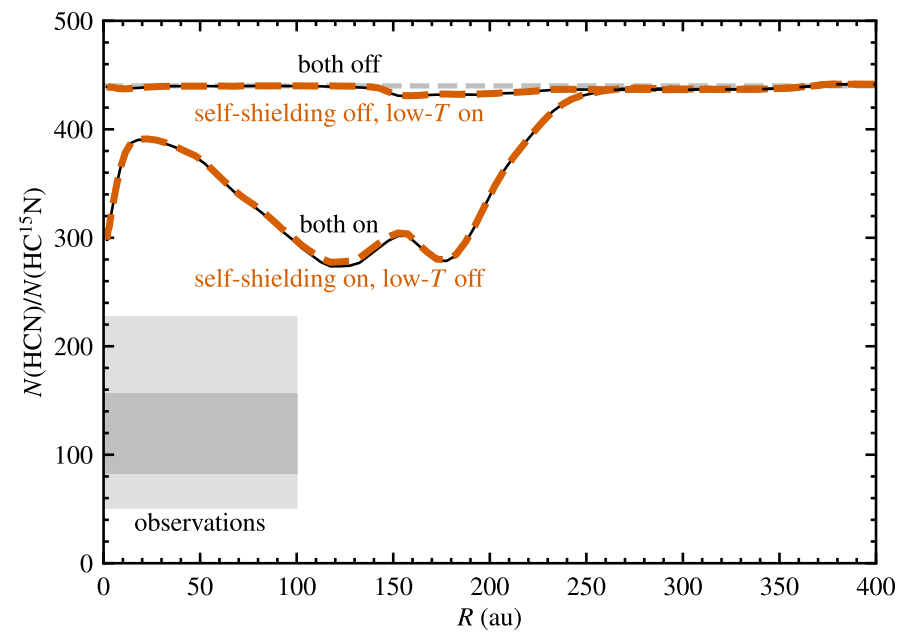

Fig. 12. Column density ratio of $\mathrm{HCN} / \mathrm{HC}^{15} \mathrm{~N}$ at $1 \mathrm{Myr}$ as a function of radius in the fiducial disk model for four variations of the chemical network: low-temperature exchange reactions on or off and self-shielding of $\mathrm{N}_{2}$ on or off. The dashed gray line marks the elemental ${ }^{14} \mathrm{~N} /{ }^{15} \mathrm{~N}$ ratio of 440 . The dark and light gray shaded regions indicate the range of observed ratios and uncertainties from Guzmán et al. (2017), probing material out to $100 \mathrm{au}$.

Figure 13 shows how the $\mathrm{HCN} / \mathrm{HC}^{15} \mathrm{~N}$ abundance ratios change when modifying one parameter at a time: disk mass, flaring angle, grain size distribution or stellar spectrum. Figure 14 shows the corresponding column density ratios. Despite obvious differences in both figures, the key point here is how little the column density ratios in the inner 100 au change across all model variations. The largest effect is seen when changing the grain size distribution, but even then the model ratios change by less than $50 \%$. The lack of variation in the model $\mathrm{HCN} / \mathrm{HC}^{15} \mathrm{~N}$ column density ratios echoes the narrow range of values observed by Guzmán et al. (2017) in a sample of six disks with different characteristics, although the observed ratios are about a factor of 2 lower than the model ratios.

Increasing the disk mass (while keeping all other parameters constant) leads to higher densities at every point in the disk, and thus also to larger optical depths. Both formation and fractionation of $\mathrm{HCN}$ are governed by the UV field; the former through vibrational excitation of $\mathrm{H}_{2}$, the latter through selfshielding of $\mathrm{N}_{2}$. As excitation of $\mathrm{H}_{2}$ moves up to higher altitudes, so does the layer with high cyanide abundances. Likewise, as $\mathrm{N}_{2}$ becomes self-shielded at greater $z / R$, the region of strong isotope fractionation also moves up. The net result is no significant change in the column density ratios of $\mathrm{HCN} / \mathrm{HC}^{15} \mathrm{~N}$ in the inner 100 au (Fig. 14, first panel).

Increasing the scale height angle exponent leads to a more strongly flared disk, where the outer parts intercept more stellar radiation than in a flatter disk. The layer with high $\mathrm{HCN}$ abundances and the layer with strong fractionation both move down in the inner disk and remain at the same altitude in the outer disk. The effects on $N(\mathrm{HCN}) / N\left(\mathrm{HC}^{15} \mathrm{~N}\right)$ in the inner 100 au are again small (Fig. 14, second panel).

Bigger changes in the column density ratios are seen when changing the grain size distribution, as already noted by Heays et al. (2014). Decreasing the fraction of large grains from $90 \%$ to $10 \%$ leads to an increase in grain surface area per unit gas density. Hence, for the same column density of gas, the UV flux is attenuated more strongly by the dust. This reduces the importance of self-shielding, resulting in lower levels of isotope fractionation (Fig. 13, bottom row, third panel). The model with $f_{\mathrm{L}}=0.1$ therefore has a higher $\mathrm{HCN} / \mathrm{HC}^{15} \mathrm{~N}$ column density ratio than the fiducial model with $f_{\mathrm{L}}=0.9$ (Fig. 14, third panel). Likewise, an increase in $f_{\mathrm{L}}$ from 0.9 to 0.99 results in somewhat smaller column density ratios.

The last parameter we varied is the stellar spectrum, as detailed in Sect. 2.1. The fiducial spectrum represents a $\mathrm{T}$ Tauri star with a UV excess for an accretion rate of $10^{-8}$ $M_{\odot} \mathrm{yr}^{-1}\left(L_{\mathrm{FUV}}=0.018 L_{\odot}\right.$ from 6 to $\left.13.6 \mathrm{eV}\right)$. Reducing the accretion rate by one order of magnitude has little effect on the $\mathrm{HCN} / \mathrm{HC}^{15} \mathrm{~N}$ ratio (Fig. 14, last panel). The ratios also do not change significantly when going from the fiducial model to a stellar spectrum typical of a Herbig star $\left(L_{\mathrm{FUV}}=0.77 L_{\odot}\right)$, consistent with the similar ratios observed in T Tauri and Herbig stars by Guzmán et al. (2017). The external radiation field has an equally small effect on the column density ratios, even when increased to 100 times the normal value for the solar neighborhood.

\section{Conclusions}

This paper presents chemical models of nitrogen isotope fractionation in circumstellar disks with a 2D axisymmetric geometry. These are the first models to include both low-temperature isotope exchange reactions and isotope-selective photodissociation for nitrogen. Using the thermochemical code DALI, we derive abundance profiles and isotope ratios for several key nitrogen-bearing species and we study how these ratios depend on various disk parameters. 

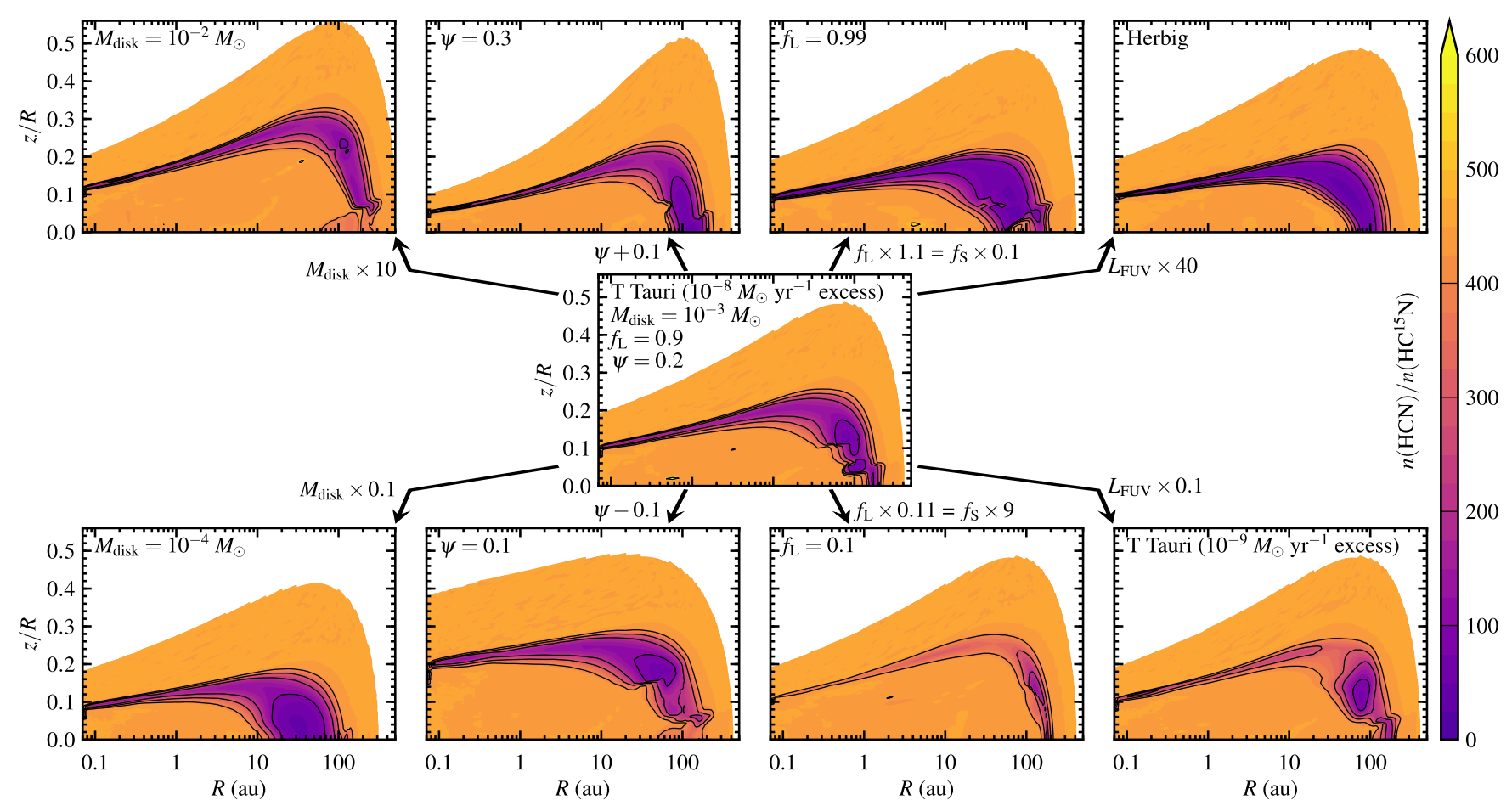

Fig. 13. Abundance ratios of $\mathrm{HCN}$ over $\mathrm{HC}^{15} \mathrm{~N}$ at $1 \mathrm{Myr}$ for several sets of model parameters. The central panel is for the fiducial model from Sect. 3 and is the same as the top center panel in Fig. 6. The other panels show the result of changing one parameter at a time, as indicated with the labels on the arrows and within the panels. Contours are drawn at ratios of 100, 200, 300, 400 and 500.

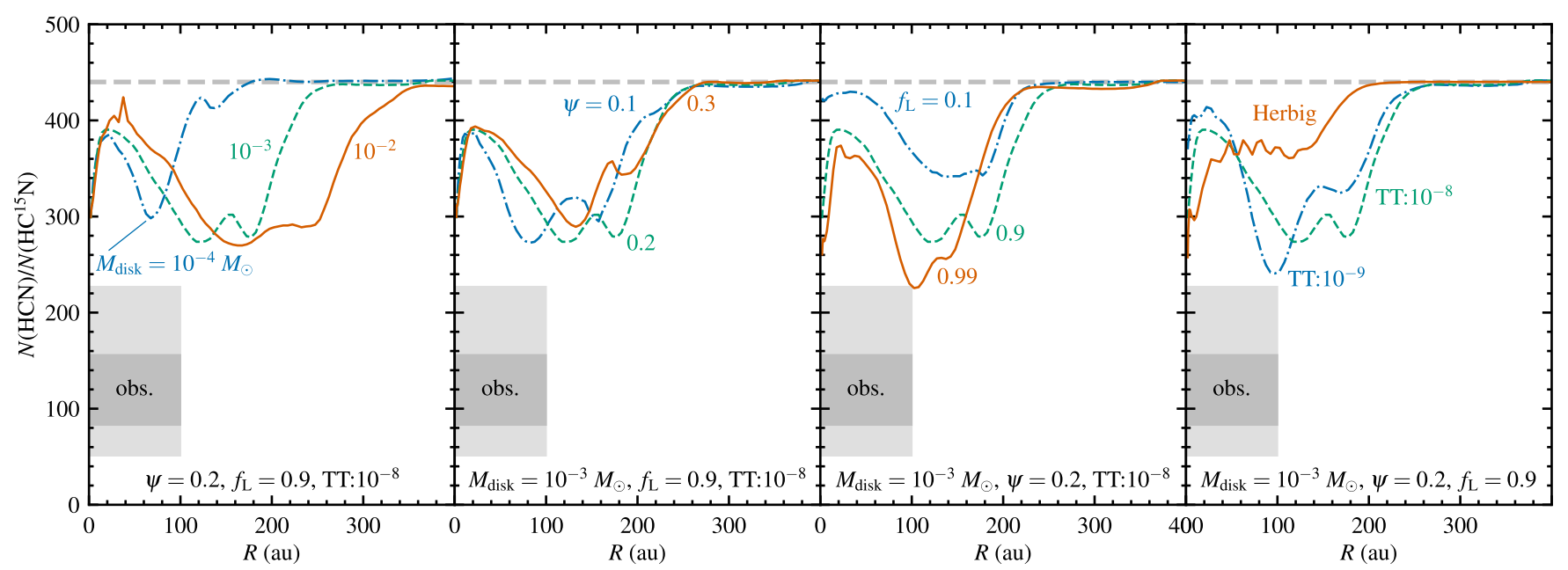

Fig. 14. Column density ratios of $\mathrm{HCN}$ over $\mathrm{HC}^{15} \mathrm{~N}$ at $1 \mathrm{Myr}$ as a function of radius for a range of model parameters: disk mass $\left(M_{\text {disk }}\right)$, flaring angle power law $(\psi)$, large grain fraction $\left(f_{\mathrm{L}}\right)$ and stellar spectrum. The dashed gray line marks the elemental ${ }^{14} \mathrm{~N} /{ }^{15} \mathrm{~N}$ ratio of 440 . The dark and light gray shaded regions indicate the range of observed $\mathrm{HCN} / \mathrm{HC}^{15} \mathrm{~N}$ ratios and uncertainties from Guzmán et al. (2017), probing material out to $100 \mathrm{au}$. The abbreviation "TT: $10^{-8}$ " means a T Tauri stellar spectrum with a UV excess for an accretion rate of $10^{-8} M_{\odot} \mathrm{yr}^{-1}$.

The formation of $\mathrm{CN}$ and $\mathrm{HCN}$ is powered by the endothermic reaction between vibrationally excited $\mathrm{H}_{2}$ and atomic $\mathrm{N}$. $\mathrm{H}_{2}$ is excited primarily through UV pumping in the irradiated surface layers and outer parts of the disk. Hence, these are the regions where the cyanides are most abundant.

Nitrogen isotope fractionation is fully dominated by isotope-selective photodissociation of $\mathrm{N}_{2}$. The low-temperature exchange reactions do not contribute at all. The lowest $\mathrm{HCN} / \mathrm{HC}^{15} \mathrm{~N}$ abundance ratio in our fiducial model is 55, representing ${ }^{15} \mathrm{~N}$ enhancement by a factor of 8 relative to the elemental ${ }^{14} \mathrm{~N} /{ }^{15} \mathrm{~N}$ ratio of 440 . The $\mathrm{HCN} / \mathrm{HC}^{15} \mathrm{~N}$ column density ratio shows a minimum of 270 and a mean of 340 in the inner 100 au. Taking uncertainties into account, these ratios are consistent with ALMA observations to within a factor of two (Guzmán et al. 2017).

Because of optical depth issues, the ${ }^{14} \mathrm{~N} /{ }^{15} \mathrm{~N}$ ratio in $\mathrm{HCN}$ is usually derived from observations of $\mathrm{H}^{13} \mathrm{CN}$ and $\mathrm{HC}^{15} \mathrm{~N}$. By also including ${ }^{13} \mathrm{C}$ in our models, we tested to what extent the standard assumption of a constant $\mathrm{HCN} / \mathrm{H}^{13} \mathrm{CN}$ ratio is justified. In the inner $100 \mathrm{au}$, probed by recent observations, the column density ratio of $\mathrm{HCN}$ to $\mathrm{H}^{13} \mathrm{CN}$ varies by less than $20 \%$ when averaged over typical beam sizes. The assumption of a constant $\mathrm{HCN} / \mathrm{H}^{13} \mathrm{CN}$ ratio is currently justified, but needs to be reevaluated if future observations probe gas at larger radii. 
The observable level of fractionation in $\mathrm{HCN}$ is largely insensitive to variations in the disk mass, the flaring angle or the stellar radiation field, but it does depend on the grain size distribution. Larger grains have a smaller surface area per unit gas volume than do smaller grains. Grain growth therefore allows for more self-shielding of $\mathrm{N}_{2}$ relative to extinction by dust and thus produces stronger levels of nitrogen isotope fractionation.

An important remaining challenge is to explain the discrepancy between the $\mathrm{HCN} / \mathrm{HC}^{15} \mathrm{~N}$ column density ratios in the models and those inferred from observations. Given the crucial role of vibrationally excited $\mathrm{H}_{2}$ in the chemistry of $\mathrm{HCN}, \mathrm{HNC}$ and $\mathrm{CN}$, the current single-level approximation (Appendix A) may not be good enough. Future work could explore a more accurate multi-level treatment.

Acknowledgements. We thank the entire DALI team for fruitful discussions Astrochemistry in Leiden is supported by the European Union A-ERC gran 291141 CHEMPLAN, by the Netherlands Research School for Astronomy (NOVA) and by a Royal Netherlands Academy of Arts and Sciences (KNAW) professor prize. All figures in this paper were made with the Python package matplotlib (Hunter 2007)

Note added in proof. Our adopted elemental ${ }^{14} \mathrm{~N} /{ }^{15} \mathrm{~N}$ ratio of 440 was also used in earlier models (e.g., Wirström et al. 2012; Roueff et al. 2015). Some observations suggest a ratio of about 300 for the present-day solar neighborhood (e.g., Ritchey et al. 2015; Hily-Blant et al. 2017). If our models were to use such an elemental ratio, the abundance and column density ratios of $\mathrm{HCN} / \mathrm{HC}^{15} \mathrm{~N}, \mathrm{CN} / \mathrm{C}^{15} \mathrm{~N}$, etc. would be lower by about a third. Isotope-selective photodissociation would remain the dominant fractionation mechanism.

\section{References}

Agúndez, M., Cernicharo, J., \& Goicoechea, J. R. 2008, A\&A, 483, 831

Agúndez, M., Goicoechea, J. R., Cernicharo, J., Faure, A., \& Roueff, E. 2010 ApJ, 713, 662

Ahn, T., Adamovich, I., \& Lempert, W. R. 2007, Chem. Phys., 335, 55

Aikawa, Y., van Zadelhoff, G. J., van Dishoeck, E. F., \& Herbst, E. 2002, A\&A 386,622

Andrews, S. M., Wilner, D. J., Espaillat, C., et al. 2011, ApJ, 732, 42

Baulch, D. L., Bowman, C. T., Cobos, C. J., et al. 2005, J. Phys. Chem. Ref. Data, 34, 757

Bockelée-Morvan, D., Calmonte, U., Charnley, S., et al. 2015, Space Sci. Rev., 197, 47

Bruderer, S. 2013, A\&A, 559, A46

Bruderer, S., van Dishoeck, E. F., Doty, S. D., \& Herczeg, G. J. 2012, A\&A, 541, A91

Bruderer, S., van der Marel, N., van Dishoeck, E. F., \& van Kempen T. A. 2014, A\&A, 562, A26

Busemann, H., Young, A. F., O’D. Alexander, C. M., et al. 2006, Science, 312, 727

Carr, J. S., \& Najita, J. R. 2008, Science, 319, 1504

Cazzoletti, P., van Dishoeck, E. F., Visser, R., Facchini, S., \& Bruderer, S. 2018, A\&A, 609, A93

Ceccarelli, C., Caselli, P., Bockelée-Morvan, D., et al. 2014, Protostars and Planets VI, 859

Cleeves, L. I., Bergin, E. A., Bethell, T. J., et al. 2011, ApJ, 743, L2

Cleeves, L. I., Bergin, E. A., Qi, C., Adams, F. C., \& Öberg, K. I. 2015, ApJ, 799, 204

D’Alessio, P., Calvet, N., Hartmann, L., Franco-Hernández, R., \& Servín, H 2006, ApJ, 638, 314

Davidson, D. F., \& Hanson, R. K. 1990, Int. J. Chem. Kinet., 22, 843

Dutrey, A., Guilloteau, S., \& Guelin, M. 1997, A\&A, 317, L55

Fedele, D., Bruderer, S., van Dishoeck, E. F., et al. 2013, ApJ, 776, L3

Floss, C., Stadermann, F. J., Bradley, J. P., et al. 2006, Geochim. Cosmochim. Acta, 70, 2371

Flower, D. R., \& Roueff, E. 1998, J. Phys. B At. Mol. Opt., 31, 2935

Fogel, J. K. J., Bethell, T. J., Bergin, E. A., Calvet, N., \& Semenov, D. 2011, ApJ, 726,29

Fonseca dos Santos, S., Balakrishnan, N., Forrey, R. C., \& Stancil, P. C. 2013, J. Chem. Phys., 138, 104302
Füri, E., \& Marty, B. 2015, Nat. Geosci., 8, 515

Gibb, E. L., Van Brunt, K. A., Brittain, S. D., \& Rettig, T. W. 2007, ApJ, 660, 1572

Graninger, D., Öberg, K. I., Qi, C., \& Kastner, J. 2015, ApJ, 807, L15

Gredel, R., Lepp, S., \& Dalgarno, A. 1987, ApJ, 323, L137

Guzmán, V. V., Öberg, K. I., Loomis, R., \& Qi, C. 2015, ApJ, 814, 53

Guzmán, V. V., Öberg, K. I., Huang, J., Loomis, R., \& Qi, C. 2017, ApJ, 836,30

Habing, H. J. 1968, Bull. Astron. Inst. Netherlands, 19, 421

Hartmann, L., Calvet, N., Gullbring, E., \& D’Alessio, P. 1998, ApJ, 495, 385

Heays, A. N., Visser, R., Gredel, R., et al. 2014, A\&A, 562, A61

Hily-Blant, P., Bonal, L., Faure, A., \& Quirico, E. 2013, Icarus, 223, 582

Hily-Blant, P., Magalhaes, V., Kastner, J., et al. 2017, A\&A, 603, L6

Hunter, J. D. 2007, Comput. Sci. Eng., 9, 90

Jehin, E., Manfroid, J., Hutsemékers, D., Arpigny, C., \& Zucconi, J.-M. 2009, Earth Moon and Planets, 105, 167

Jonkheid, B., Dullemond, C. P., Hogerheijde, M. R., \& van Dishoeck E. F. 2007, A\&A, 463, 203

Lahuis, F., van Dishoeck, E. F., Boogert, A. C. A., et al. 2006, ApJ, 636, L145

Le Bourlot J., Pineau des Forêts, G., Roueff, E., \& Flower, D. R. 1993, A\&A, 267,233

Le Bourlot J., Pineau des Forêts, G., \& Flower, D. R. 1999, MNRAS, 305, 802

Le Teuff, Y. H., Millar, T. J., \& Markwick, A. J. 2000, A\&AS, 146, 157

Li, X., Heays, A. N., Visser, R., et al. 2013, A\&A, 555, A14

Liang, M.-C., Heays, A. N., Lewis, B. R., Gibson, S. T., \& Yung, Y. L. 2007, ApJ, 664, L115

Lique, F. 2015, MNRAS, 453, 810

Loison, J.-C., Wakelam, V., \& Hickson, K. M. 2014, MNRAS, 443, 398

London, R. 1978, ApJ, 225, 405

Lucas, R., \& Liszt, H. 1998, A\&A, 337, 246

Lyons, J. R., \& Young, E. D. 2005, Nature, 435, 317

Lyons, J. R., Bergin, E. A., Ciesla, F. J., et al. 2009, Geochim. Cosmochim. Acta, 73, 4998

Mandell, A. M., Bast, J., van Dishoeck, E. F., et al. 2012, ApJ, 747, 92

Manfroid, J., Jehin, E., Hutsemékers, D., et al. 2009, A\&A, 503, 613

Markwick, A. J., Ilgner, M., Millar, T. J., \& Henning, T. 2002, A\&A, 385, 632

Marty, B., Chaussidon, M., Wiens, R. C., Jurewicz, A. J. G., \& Burnett, D. S. 2011, Science, 332, 1533

McElroy, D., Walsh, C., Markwick, A. J., et al. 2013, A\&A, 550, A36

Miotello, A., Bruderer, S., \& van Dishoeck E. F. 2014, A\&A, 572, A96

Mumma, M. J., \& Charnley, S. B. 2011, ARA\&A, 49, 471

Podio, L., Kamp, I., Codella, C., et al. 2014, ApJ, 783, L26

Ritchey, A. M., Federman, S. R., \& Lambert, D. L. 2015, ApJ, 804, L3

Rodgers, S. D., \& Charnley, S. B. 2004, MNRAS, 352, 600

Rodgers, S. D., \& Charnley, S. B. 2008a, ApJ, 689, 1448

Rodgers, S. D., \& Charnley, S. B. 2008b, MNRAS, 385, L48

Röllig, M. \& Ossenkopf, V. 2013, A\&A, 550, A56

Roueff, E., Loison, J. C., \& Hickson, K. M. 2015, A\&A, 576, A99

Salter, D. M., Hogerheijde, M. R., van der Burg, R. F. J., Kristensen, L. E., \& Brinch, C. 2011, A\&A, 536, A80

Salyk, C., Pontoppidan, K. M., Blake, G. A., et al. 2008, ApJ, 676, L49

Salyk, C., Pontoppidan, K. M., Blake, G. A., Najita, J. R., \& Carr, J. S. 2011, ApJ, 731, 130

Semenov, D., \& Wiebe, D. 2011, ApJS, 196, 25

Stecher, T. P., \& Williams, D. A. 1972, ApJ, 177, L141

Sternberg, A., Le Petit, F., Roueff, E., \& Le Bourlot J. 2014, ApJ, 790, 10

Talbi, D., Ellinger, Y., \& Herbst, E. 1996, A\&A, 314, 688

Teague, R., Guilloteau, S., Semenov, D., et al. 2016, A\&A, 592, A49

Terzieva, R., \& Herbst, E. 2000, MNRAS, 317, 563

Thi, W.-F., van Zadelhoff, G.-J., \& van Dishoeck E. F. 2004, A\&A, 425, 955

Tielens, A. G. G. M., \& Hollenbach, D. 1985, ApJ, 291, 722

van Terwisga, S. E., Van Dishoeck, E. F., Facchini, S. et al. 2018, A\&A, in press, DOI: $10.1051 / 0004-6361 / 21832862$

Visser, R., van Dishoeck, E. F., \& Black, J. H. 2009, A\&A, 503, 323

Visser, R., Doty, S. D., \& van Dishoeck E. F. 2011, A\&A, 534, A132

Wakelam, V., Herbst, E., Loison, J.-C., et al. 2012, ApJS, 199, 21

Walsh, C., Millar, T. J., \& Nomura, H. 2010, ApJ, 722, 1607

Wampfler, S. F., Jørgensen, J. K., Bizzarro, M., \& Bisschop, S. E. 2014, A\&A, 572, A24

Watson, W. D., Anicich, V. G., \& Huntress, Jr. W. T. 1976, ApJ, 205, L165

Wirström, E. S., \& Charnley, S. B. 2018, MNRAS, 474, 3720

Wirström, E. S., Charnley, S. B., Cordiner, M. A., \& Milam, S. N. 2012, ApJ, 757, L11

Woodall, J., Agúndez, M., Markwick-Kemper, A. J., \& Millar, T. J. 2007, A\&A, 466, 1197

Woods, P. M., \& Willacy, K. 2009, ApJ, 693, 1360

Zeng, S., Jiménez-Serra, I., Cosentino, G., et al. 2017, A\&A, 603, A22 


\section{Appendix A: Vibrationally excited $\mathrm{H}_{2}$}

\section{A.1. Introduction}

In the disk's surface layers, the stellar UV field can pump molecular hydrogen into a range of vibrationally excited states. The excess vibrational energy is available to overcome reaction barriers (Stecher \& Williams 1972; Tielens \& Hollenbach 1985; Agúndez et al. 2010; Bruderer et al. 2012). This process is particularly important in our models for the endothermic reaction between $\mathrm{N}$ and $\mathrm{H}_{2}$ (Reaction C.3). The product $\mathrm{NH}$ reacts with $\mathrm{C}$ or $\mathrm{C}^{+}$in one of the key routes to forming the $\mathrm{C}-\mathrm{N}$ bond.

Following Tielens \& Hollenbach (1985), DALI treats vibrationally excited $\mathrm{H}_{2}$ as a single chemical species. This $\mathrm{H}_{2}^{*}$ has a weighted average energy of $30163 \mathrm{~K}$, corresponding to a vibrational pseudo-level of $v^{*}=6$ (London 1978). The abundance of $\mathrm{H}_{2}^{*}$ is set by UV pumping, spontaneous decay and collisions with $\mathrm{H}$ and $\mathrm{H}_{2}$. The UV pumping rate is 8 times the $\mathrm{H}_{2}$ photodissociation rate (Sternberg et al. 2014) and the spontaneous decay rate is $2 \times 10^{-7} \mathrm{~s}^{-1}$ (London 1978). Our current model differs from earlier DALI publications in the adopted collision rates.

DALI originally used the collision rates from Eq. A14 of Tielens \& Hollenbach (1985), which represented fits to a small set of computational and experimental data from the 1960s and 70 s. Given the importance of $\mathrm{H}_{2}^{*}$ for the cyanide abundances, we implemented new collision rates based on more recent and more extensive computational studies. Approximations remain necessary, as described below, because specific rates into or out of the $v=6$ level are not available in the literature.

\section{A.2. Collisions between $\mathrm{H}_{2}$ and $\mathrm{H}$}

Lique (2015) computed state-to-state rovibrational rates for collisions between $\mathrm{H}_{2}$ and atomic $\mathrm{H}$. The rates are tabulated for gas temperatures from 100 to $5000 \mathrm{~K}$ and for $\mathrm{H}_{2}$ states from $v, J=0,0$ to 3,8 . Ortho-para conversion is possible through reactive collisions. The 3,8 level has an energy of $22000 \mathrm{~K}$ above the ground state, so extrapolation to the $v^{*}=6$ pseudo-level at $30000 \mathrm{~K}$ is feasible.

For use in DALI, we need the overall collisional cooling or deexcitation rate from $v=6$ to 0 , averaged over an unknown population of initial rotational states. In order to extrapolate from Lique's rates, first we compute the overall cooling rates from every upper level to the 0,0 or 0,1 ground state. The fastest way for an excited $\mathrm{H}_{2}$ molecule to cool down to the ground state is usually through a cascade of multiple $\Delta v, \Delta J$ transitions.

For example, the $v, J=0,4$ level can either undergo a single $\Delta J=-4$ collision or two $\Delta J=-2$ collisions. At $300 \mathrm{~K}$, the rate coefficients from Lique (2015) are $k_{0402}=6.0 \times 10^{-14} \mathrm{~cm}^{3} \mathrm{~s}^{-1}$ for $0,4 \rightarrow 0,2$ and $k_{0200}=9.1 \times 10^{-14} \mathrm{~cm}^{3} \mathrm{~s}^{-1}$ for $0,2 \rightarrow$ 0,0 . The rate coefficient for the two $\Delta J=-2$ collisions together then becomes $\left(k_{0402}^{-1}+k_{0200}^{-1}\right)^{-1}=3.6 \times 10^{-14} \mathrm{~cm}^{3} \mathrm{~s}^{-1}$. The single $\Delta J=-4$ collision has a rate coefficient of only $2.9 \times 10^{-15} \mathrm{~cm}^{3} \mathrm{~s}^{-1}$, so the dominant deexcitation mechanism for the 0,4 level is through a mini-cascade of two $\Delta J=-2$ collisions.

We repeat this analysis to find the fastest deexcitation cascade for each $v, J$ level in Lique's dataset. The corresponding rate coefficients at $300 \mathrm{~K}$ are plotted in Fig. A.1 as a function of upper-level energy. The rates are grouped by vibrational level: $v, J=0,0$ to 0,17 (black circles), 1,0 to 1,14 (orange squares), 2,0 to 2,11 (blue triangles) and 3,0 to 3,8 (green diamonds).

The cooling rates increase from $v=0$ to 3 . However, the difference between the $v=2$ and 3 rates is only $60 \%$ at $300 \mathrm{~K}$ and disappears altogether at higher temperatures. The $v=3$ rates

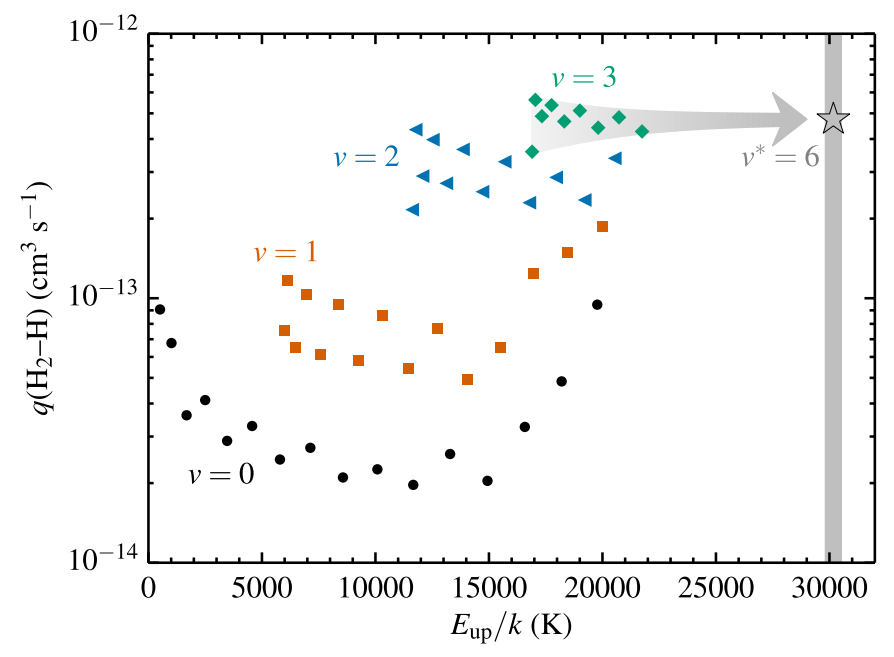

Fig. A.1. Cooling or deexcitation rate coefficients for $\mathrm{H}_{2}$ colliding with $\mathrm{H}$ at a gas temperature of $300 \mathrm{~K}$. Plotted are the overall rates from a given $v, J$ upper level to the 0,0 or 0,1 ground state, based on the fastest possible rovibrational cascade (see text). The rates are grouped by vibrational level: $v, J=0,0$ to 0,17 (black circles), 1,0 to 1,14 (orange squares), 2,0 to 2,11 (blue triangles) and 3,0 to 3,8 (green diamonds). The original state-to-state rates are from Lique (2015). The gray star marks the adopted rate for our $v^{*}=6$ pseudo-level; as indicated by the arrow, this is the average from the $v=3$ rates.

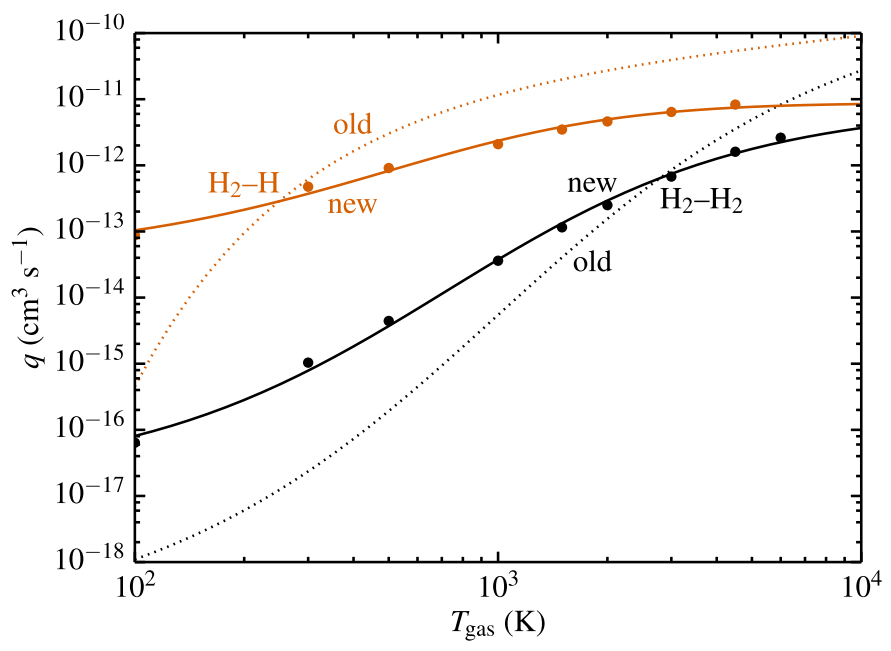

Fig. A.2. Cooling or deexcitation rate coefficients as a function of gas temperature for $\mathrm{H}_{2}$ colliding with $\mathrm{H}$ (orange) or $\mathrm{H}_{2}$ (black). The "old" rates (dotted lines) are the original implementation in DALI, based on Tielens \& Hollenbach (1985). The "new" rates (symbols and solid lines) are as described in this Appendix.

therefore appear to be a good proxy for the $v=6$ rates. Furthermore, there is little dependence on $J$ within the $v=3$ sets. At a given temperature, we thus take the average of the $v=3$ rates as the $\mathrm{H}_{2}-\mathrm{H}$ collisional deexcitation rate for the $v=6$ pseudo-level. These rates are plotted versus temperature in Fig. A.2 and the $300 \mathrm{~K}$ rate is marked with a star in Fig. A.1. For use in DALI, we fit the temperature dependence of the rates to the formula from Le Bourlot et al. (1999):

$\log \frac{q}{\mathrm{~cm}^{3} \mathrm{~s}^{-1}}=a+\frac{b}{t}+\frac{c}{t^{2}}$

where $t=1+T /(1000 \mathrm{~K})$. The fitted coefficients for the $\mathrm{H}_{2}-\mathrm{H}$ collisions are $a=-11.06, b=0.0555$ and $c=-2.390$. 


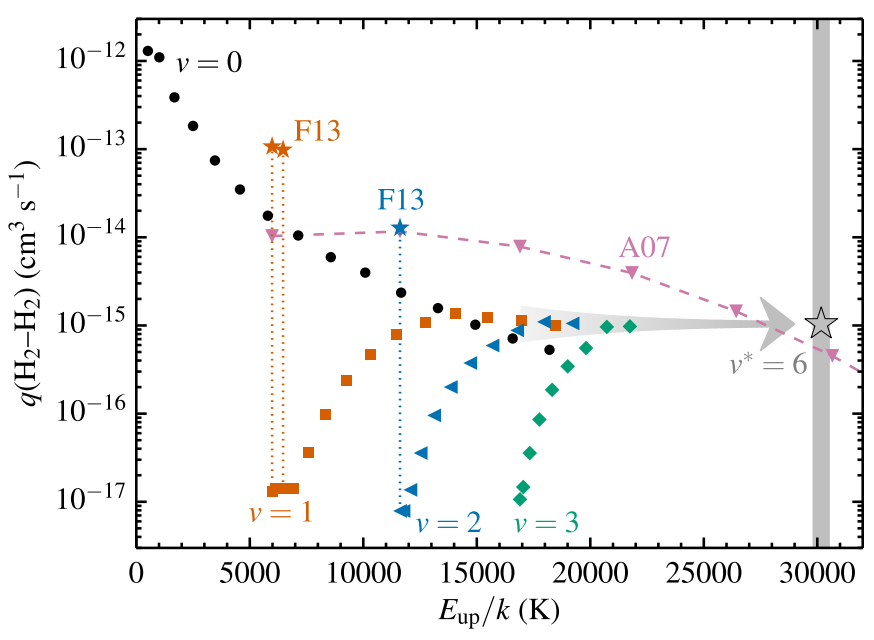

Fig. A.3. Same as Fig. A.1, but for $\mathrm{H}_{2}$ colliding with $\mathrm{H}_{2}$. The circles, squares, triangles and diamonds denote the overall cooling rate coefficients from a given $v, J$ level to the ground state based on the stateto-state rates from Flower \& Roueff (1998). The orange and blue stars show the $v, J=1,0,1,2$ and 2,0 vibration-vibration rates of Fonseca dos Santos et al. (2013). The lilac triangles and dashed curve show the VV rates of Ahn et al. (2007). The gray star marks the adopted rate for our $v^{*}=6$ pseudo-level; as indicated by the arrow, this is the rate that the $v=1,2$ and 3 series from Flower \& Roueff converge to in the high- $J$ limit.

\section{A.3. Collisions between $\mathrm{H}_{2}$ and $\mathrm{H}_{2}$}

The other set of rates is for collisions between $\mathrm{H}_{2}$ and $\mathrm{H}_{2}$. Flower \& Roueff (1998) computed state-to-state rovibrational rates up to $v, J=3,8$ at gas temperatures from 100 to $6000 \mathrm{~K}$, covering nearly the same parameter space as Lique (2015) for $\mathrm{H}_{2}-$ H. Fonseca dos Santos et al. (2013) computed rates only up to the 2,4 level $\left(E_{\mathrm{u}} / k=13000 \mathrm{~K}\right)$ and for a narrower range of temperatures. Ahn et al. (2007) performed experiments up to $v=5$ at a gas temperature of $300 \mathrm{~K}$ and used scaled semi-classical computations to estimate rates up to $v=9$.
Flower \& Roueff kept the collision partner fixed in the ground state, whereas Fonseca dos Santos et al. and Ahn et al. allowed both $\mathrm{H}_{2}$ molecules to undergo rovibrational transitions. These so-called vibration-vibration (VV) collisions are three to four orders of magnitude faster than the vibration-translation (VT) collisions from Flower \& Roueff.

As was the case for the $\mathrm{H}_{2}-\mathrm{H}$ collisions, the overall deexcitation process from a given $v, J$ level typically involves multiple $\mathrm{H}_{2}-\mathrm{H}_{2}$ collisions. We followed the same approach as above in finding the fastest cascade to compute overall cooling rates as a function of gas temperature and upper level. Figure A.3 shows the results for $300 \mathrm{~K}$ based on the state-to-state rates from Flower \& Roueff (1998). The three VV rates tabulated by Fonseca dos Santos et al. (2013) are plotted as small stars and are connected to the corresponding VT rates from Flower \& Roueff by dotted lines. The lilac triangles and dashed curve represent the rates from Ahn et al.

For the rate coefficients based on Flower \& Roueff, the $v=1,2$ and 3 series all converge to a common value of $1 \times 10^{-15} \mathrm{~cm}^{3} \mathrm{~s}^{-1}$. A similar level of convergence occurs at all other temperatures in their grid. The $v=6$ estimate at $300 \mathrm{~K}$ from Ahn et al. is $5 \times 10^{-16} \mathrm{~cm}^{3} \mathrm{~s}^{-1}$, a factor of 2 lower than the "convergence rate" derived from Flower \& Roueff. The difference between the VV and VT rates thus appears to vanish at higher $v, J$ levels than those explored by Fonseca dos Santos et al.

The study of Ahn et al. was limited to a single temperature of $300 \mathrm{~K}$. For other temperatures, the best we can do is to adopt the rates that the $v=1,2$ and 3 series from Flower \& Roueff converge to. These rates are plotted in Fig. A.2. In order to maintain a smooth temperature dependence, we also use the rate from Flower \& Roueff at $300 \mathrm{~K}$. The temperature dependence is fitted to Eq. (A.1) with $a=-11.08, b=-3.671$ and $c=-2.023$.

\section{Appendix B: List of species}

Table B.1 lists the full set of species in our chemical network with carbon and nitrogen isotopes. The network contains 205 gas-phase species and 76 ices, connected by 5751 reactions.

Table B.1. List of species in our chemical network with carbon and nitrogen isotopes.

\begin{tabular}{|c|c|c|c|c|c|c|c|c|}
\hline $\mathrm{H}$ & $\mathrm{He}$ & $\mathrm{C}$ & ${ }^{13} \mathrm{C}$ & $\mathrm{N}$ & ${ }^{15} \mathrm{~N}$ & $\mathrm{O}$ & $\mathrm{Mg}$ & $\mathrm{Si}$ \\
\hline $\mathrm{S}$ & $\mathrm{Fe}$ & $\mathrm{H}_{2}$ & $\mathrm{H}_{2}^{*}$ & $\mathrm{CH}$ & ${ }^{13} \mathrm{CH}$ & $\mathrm{CH}_{2}$ & ${ }^{13} \mathrm{CH}_{2}$ & $\mathrm{CH}_{3}$ \\
\hline${ }^{13} \mathrm{CH}_{3}$ & $\mathrm{CH}_{4}$ & ${ }^{13} \mathrm{CH}_{4}$ & $\mathrm{NH}$ & ${ }^{15} \mathrm{NH}$ & $\mathrm{NH}_{2}$ & ${ }^{15} \mathrm{NH}_{2}$ & $\mathrm{NH}_{3}$ & ${ }^{15} \mathrm{NH}_{3}$ \\
\hline $\mathrm{OH}$ & $\mathrm{H}_{2} \mathrm{O}$ & $\mathrm{C}_{2}$ & $\mathrm{C}^{13} \mathrm{C}$ & $\mathrm{C}_{2} \mathrm{H}$ & ${ }^{13} \mathrm{CCH}$ & $\mathrm{C}^{13} \mathrm{CH}$ & $\mathrm{C}_{2} \mathrm{H}_{2}$ & $\mathrm{HC}^{13} \mathrm{CH}$ \\
\hline $\mathrm{C}_{2} \mathrm{H}_{3}$ & $\mathrm{H}^{13} \mathrm{CCH}_{2}$ & $\mathrm{HC}^{13} \mathrm{CH}_{2}$ & $\mathrm{CN}$ & $\mathrm{C}^{15} \mathrm{~N}$ & ${ }^{13} \mathrm{CN}$ & ${ }^{13} \mathrm{C}^{15} \mathrm{~N}$ & $\mathrm{HCN}$ & $\mathrm{HC}^{15} \mathrm{~N}$ \\
\hline $\mathrm{H}^{13} \mathrm{CN}$ & $\mathrm{H}^{13} \mathrm{C}^{15} \mathrm{~N}$ & HNC & $\mathrm{H}^{15} \mathrm{NC}$ & $\mathrm{HN}^{13} \mathrm{C}$ & $\mathrm{H}^{15} \mathrm{~N}^{13} \mathrm{C}$ & $\mathrm{H}_{2} \mathrm{CN}$ & $\mathrm{H}_{2} \mathrm{C}^{15} \mathrm{~N}$ & $\mathrm{H}_{2}^{13} \mathrm{CN}$ \\
\hline $\mathrm{H}_{2}^{13} \mathrm{C}^{15} \mathrm{~N}$ & $\mathrm{CO}$ & ${ }^{13} \mathrm{CO}$ & $\mathrm{HCO}$ & $\mathrm{H}^{13} \mathrm{CO}$ & $\mathrm{H}_{2} \mathrm{CO}$ & $\mathrm{H}_{2}^{13} \mathrm{CO}$ & $\mathrm{CO}_{2}$ & ${ }^{13} \mathrm{CO}_{2}$ \\
\hline $\mathrm{N}_{2}$ & $\mathrm{~N}^{15} \mathrm{~N}$ & NO & ${ }^{15} \mathrm{NO}$ & HNO & $\mathrm{H}^{15} \mathrm{NO}$ & $\mathrm{O}_{2}$ & $\mathrm{C}_{2} \mathrm{~N}$ & $\mathrm{C}_{2}^{15} \mathrm{~N}$ \\
\hline${ }^{13} \mathrm{CCN}$ & ${ }^{13} \mathrm{CC}^{15} \mathrm{~N}$ & $\mathrm{C}^{13} \mathrm{CN}$ & $C^{13} C^{15} N$ & OCN & $\mathrm{OC}^{15} \mathrm{~N}$ & $\mathrm{O}^{13} \mathrm{CN}$ & $\mathrm{O}^{13} \mathrm{C}^{15} \mathrm{~N}$ & $\mathrm{SiH}^{2}$ \\
\hline $\mathrm{SiO}$ & $\mathrm{e}^{-}$ & $\mathrm{H}^{+}$ & $\mathrm{H}^{-}$ & $\mathrm{H}_{2}^{+}$ & $\mathrm{H}_{3}^{+}$ & $\mathrm{He}^{+}$ & $\mathrm{HeH}^{+}$ & $\mathrm{C}^{+}$ \\
\hline${ }^{13} \mathrm{C}^{+}$ & $\mathrm{CH}^{+}$ & ${ }^{13} \mathrm{CH}^{+}$ & $\mathrm{CH}_{2}^{+}$ & ${ }^{13} \mathrm{CH}_{2}^{+}$ & $\mathrm{CH}_{3}^{+}$ & ${ }^{13} \mathrm{CH}_{3}^{+}$ & $\mathrm{CH}_{4}^{+}$ & ${ }^{13} \mathrm{CH}_{4}^{+}$ \\
\hline $\mathrm{CH}_{5}^{+}$ & ${ }^{13} \mathrm{CH}_{5}^{+}$ & $\mathrm{N}^{+}$ & ${ }^{15} \mathrm{~N}^{+}$ & $\mathrm{NH}^{+}$ & ${ }^{15} \mathrm{NH}^{+}$ & $\mathrm{NH}_{2}^{+}$ & ${ }^{15} \mathrm{NH}_{2}^{+}$ & $\mathrm{NH}_{3}^{+}$ \\
\hline${ }^{15} \mathrm{NH}_{3}^{+}$ & $\mathrm{NH}_{4}^{+}$ & ${ }^{15} \mathrm{NH}_{4}^{+}$ & $\mathrm{O}^{+}$ & $\mathrm{OH}^{+}$ & $\mathrm{H}_{2} \mathrm{O}^{+}$ & $\mathrm{H}_{3} \mathrm{O}^{+}$ & $\mathrm{C}_{2}^{+}$ & $\mathrm{C}^{13} \mathrm{C}^{+}$ \\
\hline $\mathrm{C}_{2} \mathrm{H}^{+}$ & ${ }^{13} \mathrm{CCH}^{+}$ & $\mathrm{C}^{13} \mathrm{CH}^{+}$ & $\mathrm{C}_{2} \mathrm{H}_{2}^{+}$ & $\mathrm{HC}^{13} \mathrm{CH}^{+}$ & $\mathrm{C}_{2} \mathrm{H}_{3}^{+}$ & $\mathrm{H}^{13} \mathrm{CCH}_{2}^{+}$ & $\mathrm{HC}^{13} \mathrm{CH}_{2}^{+}$ & $\mathrm{CN}^{+}$ \\
\hline $\mathrm{C}^{15} \mathrm{~N}^{+}$ & ${ }^{13} \mathrm{CN}^{+}$ & ${ }^{13} \mathrm{C}^{15} \mathrm{~N}^{+}$ & $\mathrm{HCN}^{+}$ & $\mathrm{HC}^{15} \mathrm{~N}^{+}$ & $\mathrm{H}^{13} \mathrm{CN}^{+}$ & $\mathrm{H}^{13} \mathrm{C}^{15} \mathrm{~N}^{+}$ & $\mathrm{HNC}^{+}$ & $\mathrm{H}^{15} \mathrm{NC}^{+}$ \\
\hline $\mathrm{HN}^{13} \mathrm{C}^{+}$ & $\mathrm{H}^{15} \mathrm{~N}^{13} \mathrm{C}^{+}$ & $\mathrm{HCNH}^{+}$ & $\mathrm{HC}^{15} \mathrm{NH}^{+}$ & $\mathrm{H}^{13} \mathrm{CNH}^{+}$ & $\mathrm{H}^{13} \mathrm{C}^{15} \mathrm{NH}^{+}$ & $\mathrm{H}_{2} \mathrm{NC}^{+}$ & $\mathrm{H}_{2}^{15} \mathrm{NC}^{+}$ & $\mathrm{H}_{2} \mathrm{~N}^{13} \mathrm{C}^{+}$ \\
\hline $\mathrm{H}_{2}^{15} \mathrm{~N}^{13} \mathrm{C}^{+}$ & $\mathrm{CO}^{+}$ & ${ }^{13} \mathrm{CO}^{+}$ & $\mathrm{HCO}^{+}$ & $\mathrm{H}^{13} \mathrm{CO}^{+}$ & $\mathrm{HOC}^{+}$ & $\mathrm{HO}^{13} \mathrm{C}^{+}$ & $\mathrm{H}_{2} \mathrm{CO}^{+}$ & $\mathrm{H}_{2}^{13} \mathrm{CO}^{+}$ \\
\hline $\mathrm{H}_{3} \mathrm{CO}^{+}$ & $\mathrm{H}_{3}^{13} \mathrm{CO}^{+}$ & $\mathrm{CO}_{2}^{+}$ & ${ }^{13} \mathrm{CO}_{2}^{+}$ & $\mathrm{HCO}_{2}^{+}$ & $\mathrm{H}^{13} \mathrm{CO}_{2}^{+}$ & $\mathrm{N}_{2}^{+}$ & $\mathrm{N}^{15} \mathrm{~N}^{+}$ & $\mathrm{N}_{2} \mathrm{H}^{+}$ \\
\hline${ }^{15} \mathrm{NNH}^{+}$ & $\mathrm{N}^{15} \mathrm{NH}^{+}$ & $\mathrm{NO}^{+}$ & ${ }^{15} \mathrm{NO}^{+}$ & $\mathrm{HNO}^{+}$ & $\mathrm{H}^{15} \mathrm{NO}^{+}$ & $\mathrm{O}_{2}^{+}$ & $\mathrm{CNC}^{+}$ & $\mathrm{C}^{15} \mathrm{NC}^{+}$ \\
\hline $\mathrm{CN}^{13} \mathrm{C}^{+}$ & $\mathrm{C}^{15} \mathrm{~N}^{13} \mathrm{C}^{+}$ & $\mathrm{C}_{2} \mathrm{~N}^{+}$ & $\mathrm{C}_{2}^{15} \mathrm{~N}^{+}$ & ${ }^{13} \mathrm{CCN}^{+}$ & ${ }^{13} \mathrm{CC}^{15} \mathrm{~N}^{+}$ & $\mathrm{C}^{13} \mathrm{CN}^{+}$ & $\mathrm{C}^{13} \mathrm{C}^{15} \mathrm{~N}^{+}$ & $\mathrm{C}_{2} \mathrm{NH}^{+}$ \\
\hline $\mathrm{C}_{2}^{15} \mathrm{NH}^{+}$ & ${ }^{13} \mathrm{CCNH}^{+}$ & ${ }^{13} \mathrm{CC}^{15} \mathrm{NH}^{+}$ & $\mathrm{C}^{13} \mathrm{CNH}^{+}$ & $\mathrm{C}^{13} \mathrm{C}^{15} \mathrm{NH}^{+}$ & $\mathrm{OCN}^{+}$ & $\mathrm{OC}^{15} \mathrm{~N}^{+}$ & $\mathrm{O}^{13} \mathrm{CN}^{+}$ & $\mathrm{O}^{13} \mathrm{C}^{15} \mathrm{~N}^{+}$ \\
\hline $\mathrm{HNCO}^{+}$ & $\mathrm{H}^{15} \mathrm{NCO}^{+}$ & $\mathrm{HN}^{13} \mathrm{CO}^{+}$ & $\mathrm{H}^{15} \mathrm{~N}^{13} \mathrm{CO}^{+}$ & $\mathrm{Mg}^{+}$ & $\mathrm{Si}^{+}$ & $\mathrm{SiH}^{+}$ & $\mathrm{SiH}_{2}^{+}$ & $\mathrm{SiO}^{+}$ \\
\hline $\mathrm{SiOH}^{+}$ & $\mathrm{S}^{+}$ & $\mathrm{Fe}^{+}$ & $\mathrm{PAH}^{0}$ & $\mathrm{PAH}^{+}$ & $\mathrm{PAH}^{-}$ & PAH:H & & \\
\hline
\end{tabular}

Notes. Section 2.2 describes the network in full. $\mathrm{H}_{2}^{*}$ is vibrationally excited $\mathrm{H}_{2} . \mathrm{C}$ and $\mathrm{N}$ without superscripts denote ${ }^{12} \mathrm{C}$ and ${ }^{14} \mathrm{~N}$. PAH ${ }^{0}$, PAH ${ }^{+}$and $\mathrm{PAH}^{-}$are neutral and ionized PAHs, and PAH:H is a hydrogenated PAH. All neutral species except PAHs are present in the gas phase and as ice; PAHs, $\mathrm{e}^{-}$and all ions are present in the gas only. 


\section{Appendix C: Formation, conversion and destruction of $\mathrm{HCN}, \mathrm{HNC}$ and $\mathrm{CN}$}

The cyanide abundances throughout the disk are dominated by just a few formation and destruction reactions. Each of the initial nitrogen reservoirs $\left(\mathrm{NH}_{3}\right.$ ice, $\mathrm{N}$ and $\left.\mathrm{N}_{2}\right)$ can be converted into $\mathrm{HCN}, \mathrm{HNC}$ and $\mathrm{CN}$. The first such pathway starts with evaporation of $\mathrm{NH}_{3}$ ice followed by proton transfer:

$$
\begin{array}{r}
\mathrm{NH}_{3}+\mathrm{H}_{3} \mathrm{O}^{+} \rightarrow \mathrm{NH}_{4}^{+}+\mathrm{H}_{2} \mathrm{O} \\
\mathrm{NH}_{4}^{+}+\mathrm{C} \rightarrow \mathrm{HCNH}^{+}+\mathrm{H}_{2} \\
\mathrm{H}_{2} \mathrm{NC}^{+}+\mathrm{H}_{2},
\end{array}
$$

Proton transfer to $\mathrm{NH}_{3}$ also occurs from $\mathrm{HCO}^{+}, \mathrm{H}_{3}^{+}$and other ions. The products $\mathrm{HCNH}^{+}$and $\mathrm{H}_{2} \mathrm{NC}^{+}$undergo proton transfer or recombine with an electron to produce $\mathrm{HCN}, \mathrm{HNC}$ and $\mathrm{CN}$ (Loison et al. 2014).

The second cyanide formation pathway involves atomic $\mathrm{N}$ and vibrationally excited $\mathrm{H}_{2}$ (Tielens \& Hollenbach 1985; Bruderer et al. 2012):

$\mathrm{N}+\mathrm{H}_{2}^{*} \rightarrow \mathrm{NH}+\mathrm{H}$

$\mathrm{NH}+\mathrm{C} \rightarrow \mathrm{CN}+\mathrm{H}$

$\mathrm{NH}+\mathrm{C}^{+} \rightarrow \mathrm{CN}^{+}+\mathrm{H}$.

Reaction C. 3 has a barrier of 12650 K (Davidson \& Hanson 1990), so the rate with ground-state $\mathrm{H}_{2}$ is negligibly slow below gas temperatures of $\sim 1200 \mathrm{~K}$. The intermediate $\mathrm{CN}^{+}$from Reaction C.5 is hydrogenated to $\mathrm{HCNH}^{+}$, which recombines to $\mathrm{HCN}$, $\mathrm{HNC}$ and $\mathrm{CN}$. A variation of the above scheme involves $\mathrm{NH}$ reacting with $\mathrm{O}$ to $\mathrm{NO}$, followed by $\mathrm{NO}$ reacting with $\mathrm{C}$ to $\mathrm{CN}$ or with $\mathrm{CH}$ to $\mathrm{HCN}$.

Of course, there are several other sets of reactions to form cyanides out of atomic nitrogen, such as

$\mathrm{N}+\mathrm{CH}_{2} \rightarrow \mathrm{HCN}+\mathrm{H}$

and

$\mathrm{N}+\mathrm{C}_{2} \mathrm{H} \rightarrow \mathrm{C}_{2} \mathrm{~N}+\mathrm{H}$

$\mathrm{C}_{2} \mathrm{~N}+\mathrm{N} \rightarrow \mathrm{CN}+\mathrm{CN}$

and

$\mathrm{N}+\mathrm{OH} \rightarrow \mathrm{NO}+\mathrm{H}$

$\mathrm{C}+\mathrm{NO} \rightarrow \mathrm{CN}+\mathrm{O}$

$\mathrm{CH}+\mathrm{NO} \rightarrow \mathrm{HCN}+\mathrm{O}$.

None are as important as the $\mathrm{H}_{2}^{*}$ route, but they all play a supporting role at various points in the disk.

The third and final set of formation routes starts from $\mathrm{N}_{2}$ :

$\mathrm{N}_{2}+\mathrm{He}^{+} \rightarrow \mathrm{N}+\mathrm{N}^{+}+\mathrm{He}$

$\mathrm{N}^{+} \stackrel{\mathrm{H}_{2}}{\longrightarrow} \mathrm{NH}^{+} \stackrel{\mathrm{H}_{2}}{\longrightarrow} \mathrm{NH}_{2}^{+} \stackrel{\mathrm{H}_{2}}{\longrightarrow} \mathrm{NH}_{3}^{+} \stackrel{\mathrm{H}_{2}}{\longrightarrow} \mathrm{NH}_{4}^{+}$, where the intermediate products $\mathrm{NH}_{4}^{+}$and $\mathrm{N}$ feed into Reactions C.2, C.3, C.6, C.7 and C.9 to produce $\mathrm{HCN}$, HNC and $\mathrm{CN}$.

Once formed, the three cyanide species can be converted into each other via several sets of reactions. In the surface layers of the disk, photodissociation reduces $\mathrm{HCN}$ and $\mathrm{HNC}$ to $\mathrm{CN}$ :

$\mathrm{HCN}+h v \rightarrow \mathrm{CN}+\mathrm{H}$
$\mathrm{HNC}+h v \rightarrow \mathrm{CN}+\mathrm{H}$.

The second set of conversion reactions starts with proton transfer to $\mathrm{HCN}$ or $\mathrm{HNC}$ (from e.g. $\mathrm{HCO}^{+}, \mathrm{H}_{3} \mathrm{O}^{+}$or $\mathrm{H}_{3}^{+}$), followed by

$$
\begin{aligned}
\mathrm{HCNH}^{+}+\mathrm{NH}_{3} \rightarrow & \mathrm{HCN}+\mathrm{NH}_{4}^{+} \\
& \mathrm{HNC}+\mathrm{NH}_{4}^{+}
\end{aligned}
$$

or

$$
\begin{aligned}
\mathrm{HCNH}^{+}+\mathrm{e}^{-} \rightarrow & \mathrm{HCN}+\mathrm{H} \\
& \mathrm{HNC}+\mathrm{H} \\
& \mathrm{CN}+\mathrm{H}_{2} .
\end{aligned}
$$

The two or three products have roughly equal branching ratios (Loison et al. 2014). Lastly, there are three important neutralneutral conversion reactions:

$$
\begin{aligned}
\mathrm{CN}+\mathrm{H}_{2} & \rightarrow \mathrm{HCN}+\mathrm{H} \\
\mathrm{HNC}+\mathrm{C} & \rightarrow \mathrm{HCN}+\mathrm{C} \\
\mathrm{HNC}+\mathrm{H} & \rightarrow \mathrm{HCN}+\mathrm{H} .
\end{aligned}
$$

Reaction C.18 has an activation barrier of $960 \mathrm{~K}$ (Baulch et al. 2005), while the rate of Reaction C.19 is constant with temperature (Loison et al. 2014). Reaction C.20 uses the twocomponent fit from Le Teuff et al. (2000) to the quantum chemical computations of Talbi et al. (1996): $k=10^{-15} \mathrm{~cm}^{3} \mathrm{~s}^{-1}$ below $100 \mathrm{~K}$ and $k=1.36 \times 10^{-13}(T / 300 \mathrm{~K})^{4.48} \mathrm{~cm}^{3} \mathrm{~s}^{-1}$ above $100 \mathrm{~K}$.

Although plenty of reactions exist that can break the $\mathrm{C}-\mathrm{N}$ bond in HCN and HNC, none of these are dominant anywhere in our disk models. Instead, loss of the $\mathrm{C}-\mathrm{N}$ bond occurs exclusively from $\mathrm{CN}$ through the following reactions:

$$
\begin{aligned}
& \mathrm{CN}+h v \rightarrow \mathrm{C}+\mathrm{N} \\
& \mathrm{CN}+\mathrm{N} \rightarrow \mathrm{N}_{2}+\mathrm{C} \\
& \mathrm{CN}+\mathrm{O} \rightarrow \mathrm{CO}+\mathrm{N} \\
& \mathrm{CN}+\mathrm{O}_{2} \rightarrow \mathrm{CO}+\mathrm{NO} \\
& \mathrm{OCN}+\mathrm{O} .
\end{aligned}
$$

Cleaving the $\mathrm{C}-\mathrm{N}$ bond in $\mathrm{HCN}$ or $\mathrm{HNC}$ requires conversion to $\mathrm{CN}$ via Reactions C.14, C.15 and C.17. 